\title{
Microplastics and Nanoplastics in the Freshwater and Terrestrial Environment: A Review
}

\author{
Kellie Boyle and Banu Örmeci * \\ Department of Civil and Environmental Engineering, Carleton University, 1125 Colonel By Drive, Ottawa, \\ ON K1S 5B6, Canada; KellieBoyle@cmail.carleton.ca \\ * Correspondence: banuormeci@cunet.carleton.ca
}

Received: 14 August 2020; Accepted: 14 September 2020; Published: 21 September 2020

\begin{abstract}
This review is a critical analysis of current freshwater and terrestrial research with an emphasis on transport, behaviour, fate and subsequent ecological impacts that plastic pollution poses. The current methods of extraction and evaluation of organic-rich samples are also explored for both micro- and nanoplastics. Furthermore, micro- and nanoplastics are discussed with reference to their environmental and health implications for biota. Regulations imposed on the manufacture and distribution of plastics globally are also noted. Within the review, the current literature has been presented and knowledge gaps identified. These include the characterization and quantification of micro- and nanoplastics entering and forming within the freshwater and terrestrial environment, the fate and behaviour of micro- and nanoplastics under varying conditions and the impacts of microand nanoplastics on freshwater and terrestrial ecosystems.
\end{abstract}

Keywords: fate; transport; impact; sampling; quantification; characterization

\section{Introduction}

Plastic has become one of the most ubiquitous materials since its inception in 1907 as phenol-formaldehyde resin (i.e., Bakelite) [1]. The creation of plastic and its subsequent mass production has resulted in the current throw-away culture, where a large proportion of plastics are single-use. When plastic was originally introduced it was thought that its imperviousness to water and extreme versatility made it a dream material. Although these attributes do make plastic a very useful material, they also influence its impact on the Earth. An estimated 348 million tons of plastic were produced globally in 2017 as compared to 1.5 million tons in 1950 [2]. The increased production rate, low recycling rate and lack of plastic degradation has created a sizeable problem-plastics are accumulating at alarming rates in the environment.

The majority of microplastic research has been conducted in marine environments, which has identified a missing link: there is much more plastic discharged into the environment than marine sampling methods are recording [3]. This gap has helped to emphasise the need for freshwater and terrestrial micro- and nanoplastic research. Microplastics have infiltrated not only marine environments, but also freshwater and land environments [4-13]. It may even be that the freshwater and terrestrial sink of microplastics is larger than that of the oceans [11,12], with possibly from 4 to $23 \times$ the amount of plastic [13]. The need to explore the freshwater and terrestrial sink for micro- and nanoplastics is critical to develop an integrative mass-balance model of micro- and nanoplastics in the global environment. The objective of this review is to evaluate the current understanding of micro- and nanoplastics in freshwater and terrestrial environments and identify the knowledge gaps and key areas of focus for future studies. 


\section{Plastics and Their Additives}

The ambiguity of the name 'plastic' can be misleading to the average consumer; there are a plethora of materials that fall within this definition which have very different characteristics. The International Union of Pure and Applied Chemistry (IUPAC) defines plastic as a "polymeric material that may contain other substances to improve performance and reduce costs" [14]. However, a keyword that is missing from the definition is "synthetic". There are many types of polymer and each can be categorized as natural or synthetic. Natural polymers-silk, wool, starch, cellulose, proteins and DNA - are often water-based and constitute the majority of living tissue structures $[3,15,16]$. Synthetic polymers-polyethylene terephthalate (PET), high-density polyethylene (HDPE), polyvinyl chloride (PVC), low-density polyethylene (LDPE), polypropylene (PP), polystyrene (PS) and polyurethane (PUR) - are manufactured using raw materials such as coal, oil and natural gas and are classified as plastic [3]. 90\% of the total world plastic production consists of PET, HDPE, PVC, LDPE, PP, PS and PUR [17]. Additionally, there are two other types of plastic that do not fall into either the natural or synthetic category: biodegradable plastic and bioplastic. Biodegradable plastic can originate from both petroleum-based resources or biomass-based resources and bioplastic from only biomass-based resources [18]. Both of these types of plastic have been labelled as alternatives to synthetic plastic, because they will biodegrade more readily, as their names suggest. However, there is no concrete evidence that either biodegradable plastics or bioplastics will degrade in the natural environment any better than synthetic plastics $[19,20]$.

Plastics are classified into seven categories known as resin codes. Resin code number 1 is PET, which is typically used in water bottles and juice and carbonated beverages containers, as well as in polyester clothing. It has been deemed a safe plastic for food storage and is easily recycled; however, if it is exposed to high temperatures it leaches the chemical antimony, which in various organic forms can be a potential human carcinogen [21,22]. Resin code number 2 is HDPE, which is also used for containers for liquids and beverages such as water, juice, milk, cleaning supplies and beauty products. Similar to PET, when HDPE is exposed to high temperatures, boiling water and sunlight, it can leach endocrine-disrupting agents (i.e., estrogenic chemicals or chemicals that have estrogenic behaviours) [21,22]. Estrogenic chemicals are human-made compounds that mimic estrogen and can severely impact the health and reproduction of exposed aquatic organisms. Resin code number 3 is PVC, which is most commonly employed in pipes for plumbing, but is also used for food wraps, bath toys and jackets. PVC leaches endocrine-disrupting agents (i.e., phthalates and bisphenol A (BPA)), which are considered "substances of very high concern" when in contact with water [21,22]. Resin code number 4 is LDPE, which is considered a low hazard plastic used for cling wrap, bread packaging, milk cartons, take-out coffee cups, newspapers and dry cleaning. Resin code number 5 is PP, also considered a safe plastic, which is used for a variety of items such as yogurt and take-out containers, medicines, cold weather clothing, carpets, automotive parts, lab equipment and paper currency. Resin code number 6 is PS which is most commonly used as a packaging material or for take-out food, but also extensively used in the construction/building industries and the fishing industry. Styrene is considered to be an "anticipated human carcinogen" and will leach from PS when it is in contact with hot liquids [21,22]. Lastly, resin code number 7 is an amalgamation of all the other types of plastic resins or combinations of plastic resins. These plastics are typically used for large water containers and packaging. BPA is a common additive in these types of plastics (i.e., Polycarbonate $(\mathrm{PC})$ ) and has been known to cause hormone changes, reproductive problems, asthma and obesity in humans [21,22]. Although BPA has been banned and phased out of plastic products in many countries, alternative chemicals (i.e., Bisphenol S (BPS) and Bisphenol F (BPF)) have been proven to be just as hormonally active as BPA, thus perpetuating the same health issues [23].

Plastic alone is an environmental contaminant, but its properties, when combined with other additives, can be even more harmful. Many plastic products are altered or enhanced by adding other organic compounds, sometimes making up 50\% of the product $[24,25]$. BPA, phthalate acid esters (PAEs), perfluoroalkyl substances (PFASs), nonylphenol (NP) and brominated flame retardants 
(BFRs) are all common plastic additives as well as being pollutants [26-34]. The difficulty with plastic additives, otherwise known as plasticides, is that they are typically small in molecular size and are not chemically bound to polymers, meaning they could easily dissociate from the polymer when exposed to favourable conditions [3,35]. For example, compounds (e.g., phthalates), which are not lipophilic in nature, can easily dissociate when exposed to water [12]. Once contaminants are free-floating, they can also easily sorb to other polymeric substances allowing for long-range transport [3].

\section{Plastic Degradation in the Environment}

Plastics can be broken down into macroplastics ( $>25 \mathrm{~mm})$, mesoplastics (5-25 mm), microplastics $(<5 \mathrm{~mm})$ and nanoplastics $(<0.1 \mu \mathrm{m})$ via a variety of pathways [4]. There are both abiotic and biotic means of degradation that occur in the environment and they can happen simultaneously. Abiotic degradation is the mechanical degradation of plastics through weather and climate changes (e.g., freezing, thawing, pressure changes, water turbulence and damage by animal activities) [3]. However, the molecular bonds of the plastic are not impacted; only morphological changes occur.

The molecular bonds of plastic materials are most profoundly impacted by photo, thermal, oxidative and hydrolytic degradation. However, of these, photodegradation causes the most damage to plastics in the environment. UV (290-400 nm) and visible light spectra (400-700 nm) cause increased electron activity within the polymeric bonds resulting in oxidation and eventual cleavage of the bonds [36].

Thermal degradation is the breakdown of plastics in temperatures of 375 to $500{ }^{\circ} \mathrm{C}$. Due to the intense heat, bond scission of the main polymeric chains results in changes in tensile strength, molecular weight, crystallinity and colour. Thermal degradation is not typically observed in microplastic environments because temperatures will not reach the levels necessary for degradation. However, it is important to note that some plastics are thermally treated during production and are more easily biodegraded in the environment [37].

Oxidation is thermal or photo-induced and introduces oxygen to the polymer matrix leading to carbonyl (CO) and hydroxyl (HO) group formations. The $\mathrm{CO}$ and $\mathrm{HO}$ groups then help to promote biotic degradation. Oxidation by ozone in the environment is beneficial for the breakdown of plastics because it can break the covalent bonds, yielding cross-linking and chain scission reactions producing free radicals. Once free radicals are produced, the degradation of the plastic will accelerate [3,37].

Hydrolytic degradation can only occur if the polymer possesses covalent bond groups such as ester and ether groups. Covalent bond groups are targeted by hydrolytic action resulting in changes in the molecular weight and thus, the strength of the plastic [37].

Biotic degradation is degradation resulting from organism activity. Organisms will secrete enzymes that cleave the plastic polymer chains by hydrolytic processes, resulting in a reduction of molecular weight [3]. The loss of molecular weight then triggers further microbial degradation, enhanced by water and oxygen exposure, leading to the continuing loss of molecule structure over time [37]. Biotic degradation of plastic finally results in water-soluble oligomers and monomers, which can then mineralize and be assimilated as carbon and nitrogen sources by microorganisms [35]. Although the bioassimilation of plastic is typically not complete, there have been studies that demonstrated up to $60-80 \%$ assimilation of plastics (such as PE) in composting conditions over 180 days [38]. Additionally, preliminary research has shown that certain types of fungi have the ability to degrade PUR [39]; however, more analysis needs to be undergone to determine this potential application.

\section{Microplastics: Size, Shape and Density}

The size, shape, colour and density of microplastics all play a role in its bioavailability and degradation. Microplastics are typically categorized as plastics $<5 \mathrm{~mm}$ in size $[40,41]$ or between $1 \mu \mathrm{m}$ to $5 \mathrm{~mm}$ [13]; however, there have been studies that report them as $<1 \mathrm{~mm}$ [42], $<2 \mathrm{~mm}$ [43], 2-6 $\mathrm{mm} \mathrm{[44]} \mathrm{and} \mathrm{<10} \mathrm{mm} \mathrm{[45].}$ 
Fragments, pellets, filaments and fibres, broken edges, granules and irregularly shaped microplastics are the most common forms microplastics take in the environment [17]. However, synthetic fibres and microbeads are more commonly discussed due to their pervasiveness in daily life. Textiles, such as clothing, result in the release of synthetic fibres through ordinary use and laundering $[7,46]$. Similarly, microbeads are commonly found in everyday beauty and hygiene products, as well as cleaning products, which are washed down drainage systems $[6,35,47]$. Once fibres become airborne and, along with microbeads, are released into water, they are very difficult to retrieve and can easily become deposited in freshwater and terrestrial environments.

Microplastic shapes are determined by three key factors: the original plastic form, degradation of the plastic and residence time in the environment. The longer a plastic is in the environment, the more rounded and smooth its edges will become [48]. Reactivity, different sizes and shapes, and the high surface to volume ratio of microplastics make them extremely dynamic. The different properties of each particle will alter or enhance its bioavailability within the environment, thus making sampling and quantification difficult.

Typically, plastics with a specific gravity (SG) of $<1$ will sink when exposed to water and those with an SG of $>1$ will float; however, the SG or density of plastics will vary depending on heteroaggregation and microbial colonization. Biofouling and biofilm development, which occur as a result of microbial activity, will then attract invertebrates and algae, further altering the specific gravity. This, along with water currents and interaction with biota, means that microplastics have infiltrated the entire water column in both marine and freshwater environments $[3,49,50]$.

\section{Nanoplastics: Size, Shape and Density}

Nanoplastics, which are too small to be seen by the naked eye, are similar to microplastics in that they have not been given a standard size definition. However, more frequently nanoplastics are referred to as plastic particles that are $<0.1 \mu \mathrm{m}$ in size [4]. Nanoplastics are largely the result of the breakdown of macro- and microplastics into micro- and nanometre sized particles-the smallest plastic particles. Due to their size, nanoplastics have not been adequately researched and are thus difficult to characterize. However, some commercial sources of nanoplastics include beauty and hygiene products, specifically those with exfoliating properties, abrasive cleaning supplies, air-blasting mechanisms, and plastic powders used to make larger plastics [42,51,52].

\section{Sources, Pathways and Sinks}

The sources of plastics entering the environment are extremely varied. Many everyday activities contribute to innumerable quantities of micro- and nanoplastics in the environment [7]. Laundering clothing that contains synthetic materials, such as acrylic, fleece and polyester, contributes to one million tons per year of synthetic fibres entering wastewater streams, $50 \%$ of which enters the environment $[7,46]$. Another consistent producer of microplastics in wastewater streams are exfoliants and toothpaste: per $1.6 \mathrm{~g}$ (the average toothpaste application) there can be upwards of 4000 microbeads [51]. Once micro- and nanoplastics enter wastewater it is difficult to remove them before that water is either recycled or discharged to the environment [51,53-55]. Degradation of tires [56-58], resulting in tire dust, can produce upwards of $1400 \mathrm{mg}$ of microplastics per $\mathrm{km}$ and paint [7], such as that used for road markings and house exteriors, accounts for $10 \%$ of the microplastic pollution entering the environment [7].

Microplastics in the environment can be broken down into two categories: primary and secondary [59]. The primary sources of microplastics are engineered as microbeads in hygiene and beauty products (e.g. exfoliants), as industrial abrasives, as pellets for fabrication of larger plastic products $[6,35,47]$ and from $3 \mathrm{D}$ printer emissions [60]. Typically, primary sources have defined shapes, sizes and densities. However, secondary sources come from the breakdown and fragmentation of larger plastics already in the environment due to accidental release or littering. The degradation of macroplastics $(>25 \mathrm{~mm})$, mesoplastics $(5-25 \mathrm{~mm})$ and microplastics leads to irregular microplastic 
shapes, sizes and densities and different chemical compositions [52]. It is difficult to identify primary sources of microplastics in the environment due to the exposure to the elements that result in secondary microplastics. Secondary microplastics are the most commonly seen in the environment due to exposure to UV radiation and physical abrasion [61].

There are both direct and indirect ways that micro- and nanoplastics enter the environment. Direct means of contamination is when plastic is purposefully applied or used, such as in plastic mulch, greenhouse building materials and soil conditioners [4,12]. Many micro- and nanoplastics are retained in wastewater even after it has been treated at a wastewater treatment plant (WWTP) and those that are not retained end up in the sludge $[51,53-55,62,63]$. Two major indirect routes that micro- and nanoplastics take are via the use of urban and industrial wastewater (treated or untreated) irrigation and sludge land applications [52,64]. Additionally, WWTP and industrial effluents are commonly released to surface waters or may even be directly injected into aquifers for managed aquifer recharge (MAR), which provides another route of contamination of freshwater resources [65]. Other common indirect routes are accidental release, indiscriminate discards and inappropriate disposal methods [48]. Heavily industrialised areas result in accidental release during manufacture, transport and use, which contributes significantly to micro- and nanoplastic pollution [66].

Plastics from the oceans can also be categorized as an indirect source of plastics on land. Ekman currents (the strong vortices in the oceans) maintain the build-up of plastics in specific oceanic gyres/zones, and in combination with anthropogenic (human) activity plastics become prevalent along coastlines [3]. The anthropogenic activities that emit plastics to the ocean from the land would be considered an indirect source to the oceans; however, the build-up of microplastics in these zones along with the ocean currents, results in the migration of microplastics to other land areas. Thus, coastal land can become contaminated with microplastics from sources other than those in the immediate area due to oceanic movements.

Lakes and fluvial networks (rivers and their tributaries) are a major sink for micro- and nanoplastics $[8,49,67]$. Run-off occurs from surrounding urban and rural landscapes, as well as discharge from WWTPs and stormwater drains, supply lakes, rivers and streams containing macro-, micro- and nanoplastics. Rivers and their tributaries also transport macro-, micro- and nanoplastics to larger bodies of freshwater (i.e., lakes, ponds and wetlands), as well as to the ocean. The movement of plastics with the river currents can then result in indirect deposition of macro-, micro- and nanoplastics on banks and shorelines far from the original source of contamination.

Once plastics are deposited on soils or sediments they can be remobilized by weather and climate patterns in the region. Depending on storm events or planned irrigation, run-off will occur, resulting in the movement of plastics into water streams. However, wind events can also cause movement of plastics both to freshwater systems as well as to other terrestrial environments. Macro- and micro-plastic litter can easily be moved by wind-studies have shown that microplastic fibres have been found in significant concentrations in the atmosphere $[68,69]$. The deposition of macro- and microplastics is therefore a likely source of contamination in the terrestrial and freshwater environments.

\section{Freshwater Sampling and Monitoring Methods}

Freshwater samples can be taken from the surface of the water, within the water column and from sediments, each requiring different techniques. There are three general methods used: selective, bulk or volume-reduced $[70,71]$. Selective samples are used when microplastics are visible on water or sediment surfaces, only requiring a bottle or container to collect the sample (i.e., grab samples). Volume reduced or bulk samples (such as core, trap, composite or pumped samples) are more intensive and time-consuming, but more accurately represent the sampling area. Bulk samples do not filter out any of the water or sediment, instead gathering the entirety of the sampling area/volume. Selective and bulk sampling methods require pre-treatment (filtering or sieving) before analysis. Volume reducing samples filter the majority of the water or sediment from the sample using nets, sieves, or filters with varying levels of porosity. 
Mid-water column and benthic nets $(41,250$ and $500 \mu \mathrm{m})$ [49], neuston nets $(333 \mu \mathrm{m})[67,72,73]$, manta trawls $(100,300$ and $333 \mu \mathrm{m})$ [74-80], plankton nets $(80$ and $153 \mu \mathrm{m})[76,81]$ and sieves/filters (10-400 $\mu \mathrm{m}$ and $1-5 \mathrm{~mm})[51,80,82,83]$ are recording methods for freshwater sampling regimes at the surface and at depth in the water. However, the large ranges of porosity and methods used make data comparison very difficult between studies. Another concern is that smaller micro- and nanoplastics are bypassing the catchment methods due to the larger size limitations of the nets or filters; however, smaller porosities are impractical due to excessive clogging. Sampling methods need to be further developed to account for smaller particle sizes and to allow for standardization of sampling practices. Additionally, the ubiquity of microplastic fibres, both in the atmosphere and in equipment or clothing, makes them difficult to accurately sample in freshwater environments. Direct deposition and the consequent contamination of samples is highly probable, so methods of eradicating these biases also need to be developed.

\section{Complex and Organic-Rich Sample Pre-Treatment}

Sampling procedures and pre-treatments for micro- and nanoplastics in organic-rich environments are lacking. Organically rich samples can come from agricultural or urban land, WWTP effluents and sludge, and other freshwater resources, all of which have very different properties and components. The difficulty lies in the fact that microplastics that are less than $1 \mathrm{~mm}$ in size cannot be easily quantified and characterized when left in environmental samples. In many instances, bulk removal of the organic-rich matrices, and biogenic materials/biofilms adhering to the microplastics, is an important step prior to quantification and characterization as they can interfere with many quantification techniques (i.e., Infrared (IR) and Raman spectroscopy, pyrolysis gas chromatography mass spectrometry (Py-GC-MS), thermal extraction desorption gas chromatography mass spectrometry (TED-GC-MS), etc., or hinder the ability to distinguish characteristic features of the microplastics through microscopic analyses. Thus, after samples are collected, pre-treatment steps to isolate the plastic components may be required to fully investigate the micro- and nanoplastic pollution present.

Separating microplastics from natural organic matter (NOM) and other biogenic materials, while preserving the plastic particles, is the largest obstacle when it comes to removing microplastics from soil, WWTP effluents, sludge and other freshwater sources [46]. Treatment methods need to preserve microplastic samples so that critical information, such as the size, shape, colour and surface texture, can be retained to help determine the source, pathway and fate of the microplastics. Physical separation techniques that do not alter the polymers, such as sieving and filtering, are not an effective means of removing microplastics from an organic-rich matrix; only macroplastics can be effectively removed with these techniques $[84,85]$. The densities of microplastics are within the same range as many NOM particles $\left(0.9-1.5 \mathrm{~g} / \mathrm{cm}^{3}\right)[12,86]$ and cannot be easily separated using density and flotation separation [87-90]. Oxidation using hydrogen peroxide $\left(\mathrm{H}_{2} \mathrm{O}_{2}\right)$ has thus become one of the more common methods of separation [86]; however, studies have reported that only small fractions of biogenic material are removed [91] and the NOM (along with the plastic particles) is often bleached rather than removed [89]. Additionally, some polymers such as PE, PP and PS have been found to degrade under these conditions $[46,89]$.

Hurley et al. [86] tested $\mathrm{H}_{2} \mathrm{O}_{2}$ oxidation, Fenton's reagent $\left(\mathrm{H}_{2} \mathrm{O}_{2}\right.$ oxidation in the presence of a catalyst $\mathrm{Fe}^{2+}$ ) and alkaline digestion using $\mathrm{NaOH}$ and $\mathrm{KOH}$ on soil and sludge samples to determine which would best preserve the microplastics, while removing the most organic matter. The $\mathrm{H}_{2} \mathrm{O}_{2}$ oxidation results corroborated the findings from previous studies in that there was polymer degradation despite the effective removal of organic matter from the samples (sludge: $80-86 \%$, soil: $96-108 \%$ ). It was also found that $\mathrm{NaOH}$ alkaline digestion resulted in significant degradation of PET and PC particles but removed $61 \%-67 \%$ of the organic matter from the sludge samples and $64 \%-68 \%$ from the soil samples. $\mathrm{KOH}$ alkaline digestion had minimal impact on the plastic particles; however, it only removed $57 \%$ of the organic matter from the sludge samples and $35 \%$ from the soil samples. Ultimately, Fenton's reagent was deemed the most effective method with no noticeable polymeric degradation and 
high organic matter removal (sludge: $87 \%$, soil: 106\%). Tagg et al. [92] and Lares et al. [63] also tested Fenton's reagent and found that it was an effective means of separating microplastics from NOM in wastewater samples.

Rodrigues et al. [93] tested density separation methods in conjunction with organic matter degradation methods to see which combination was the most optimal for microplastic $(\geq 0.2 \mathrm{~mm})$ isolation in synthetic freshwater samples. Fenton's reagent and Fenton's reagent with enzymatic digestion (consisting of proteases, lipases, amylases and cellulases) were each followed by $0.2 \mathrm{~mm}$ sieving and zinc chloride $\left(\mathrm{ZnCl}_{2}\right)$ density separation, which resulted in microplastic recoveries of $96 \%$ and $95 \%$, respectively, as well as organic matter removals of $80 \%$ with no adverse effects on the microplastic particles and fragments. However, enzymatic digestion (BIOATAK) followed by $0.2 \mathrm{~mm}$ sieving and $\mathrm{ZnCl}_{2}$ density separation resulted in $96 \%$ microplastic recovery, but negligible organic matter removal. When $\mathrm{ZnCl}_{2}$ density separation was tested separately without organic matter removal or sieving, there was still a $97 \%$ microplastic recovery.

The types of plastic utilized by Rodrigues et al. [93] all had densities $<1.5 \mathrm{~g} / \mathrm{L}$, with the majority being approximately $1 \mathrm{~g} / \mathrm{L}$, which is why $\mathrm{ZnCl}_{2}$, with a density ranging from $1.5-1.6 \mathrm{~g} / \mathrm{L}$, was so effective. In natural freshwaters some of the microplastic contamination may not be as easily separated due to differing densities. Additionally, the size and structure of the organic materials present was small enough to be filtered through $0.2 \mathrm{~mm}$ sieves, which could be problematic for natural freshwater samples containing larger organic materials, organisms and biofilms. It was noted in the study that the presence of the organic matter, despite its relatively miniscule size within the samples, was a hindrance during microplastic analysis, so despite having a high microplastic recovery $\mathrm{ZnCl}_{2}$ density separation alone was not the most ideal solution. Ultimately, Fenton's reagent with $\mathrm{ZnCl}_{2}$ density separation was the most simplistic and effective method.

Conversely, other studies demonstrated that enzymatic digestion was a viable method of separating microplastics from organic matter and biogenic materials in marine and sediment samples. Cole et al. [91] demonstrated that microplastics (fibres 6-175 $\mu \mathrm{m}$ in width and $250 \mu \mathrm{m}-5 \mathrm{~mm}$ in length and particles/fragments predominantly $<250 \mu \mathrm{m}$ ) were separated from biofilm and biogenic materials using enzymatic digestion (Proteinase-K), which digested over 97\% of the biogenic material without causing adverse effects to the microplastics present. Löder and Gerdts [94] also successfully used enzymatic digestion using varying types of enzymes (lipase, amylase, proteinase, chitinase and cellulase) to isolate and purify marine, sediment and biological tissue samples prior to quantification and characterization.

Based on these studies, Fenton's reagent is a viable method for the separation of microplastics from organic-rich samples; however, its applicability for nanoplastic isolation has yet to be determined. Similarly, enzymatic digestion is a promising separation method, but further analysis must be conducted on micro- and nanoplastic particles to develop standardized procedures. It is also important to identify specific types of enzymes or combinations of enzymes optimal for the varying types of environmental samples, such as freshwater, sludge and soils. Very limited research has been conducted on its use in freshwater and terrestrial samples.

As outlined by Rodrigues et al. [93], density separation can be useful when combined with organic matter degradation (for those samples that require it), and by itself for sediment or freshwater samples that do not contain significant quantities of organic matter. Minerals in environmental samples can pose problems during quantification and analysis. Density separation of micro- and nanoplastics from minerals is typically achieved using flotation. The most standard flotation method consists of particles separating naturally based on their densities in a stagnant fluid. The other two methods are slightly more involved: separation via froth flotation and hydrodynamic flotation. Froth flotation utilizes air bubbles, which accelerates the particle separation by targeting the hydrophobic nature of the polymers. Hydrodynamic flotation utilizes hydrodynamic flow to assist density separation of the particles. There is also a multitude of different solutions that can be utilized in these methods: distilled water, saturated $\mathrm{NaCl}$, concentrated $\mathrm{ZnCl}_{2}$ and concentrated $\mathrm{NaI}$ [46]. However, flotation 
methods have yet to be proven effective for nanoplastics. Wang et al. [46] studied flotation separation for small microplastics $(<100 \mu \mathrm{m})$ and nanoplastics in sludge and soil samples using concentrated $\mathrm{ZnCl}_{2}$ and determined that $100 \%$ separation of $0.05 \mu \mathrm{m}$ particles would require a total time of $86,186 \mathrm{~h}$. Nevertheless, once the NOM and the remaining minerals are removed, quantification of the samples becomes significantly easier.

It is important to note that not all quantification techniques will require such complex sample pre-treatment or total removal of the organic-rich matrix or biofilms present. The required sample pre-treatment will also vary depending on the objectives of the conducted study. However, if size and distribution as well as surface characteristics of the microplastics are needed, more complex and time-consuming sample pre-treatments are required, especially when analyzing microplastics less of than $1 \mathrm{~mm}$ and/or nanoplastics in organic-rich matrices.

\section{Quantification and Characterization of Microplastics}

\subsection{Visual Identification}

A significant majority of characterization studies have used visual identification methods, such as the naked eye or microscopic analyses [95]. Although simplistic and inexpensive, visual identification methods do not allow for accurate identification below $500 \mu \mathrm{m}$ [94]. Additionally, with visual identification there is a much greater risk of misidentifying natural particles, such as aluminum silicate (from coal ash) [77], quartz or calcium carbonate [96] and steric acid and castor oil [53], as microplastics. Microplastic fragments and fibres are also often misidentified as cotton, rayon or other organic materials [78,97]. Visual cues, such as the bright or unnatural colours and the shininess or lustre that can typically be attributed to plastic materials, become increasingly diminished with the decreasing size of the plastic and the duration of time that that plastic has been exposed to the natural environment $[97,98]$. Many studies have demonstrated that visual identification methods are extremely unreliable with significant over-estimation or under-estimation, resulting in identification errors higher than $70 \%[13,71,78,96-98]$.

\subsection{Infrared Spectroscopy (IR)}

There are two different measurement systems for infrared (IR) spectroscopy: mid-infrared (MIR) (400-4000 $\mathrm{cm}^{-1}$ ) and near-infrared (NIR) (4000-12,500 $\left.\mathrm{cm}^{-1}\right)$. MIR spectroscopy detects different vibrational stretching and deformation (different energies) of polymeric bonds, thus distinguishing the different types of polymers in a sample. Analogously, NIR spectroscopy typically detects combinations of vibrational bands and, thus, polymers cannot be identified in that manner. Instead, polymers are recognised by the shape of the vibrational bands, not the bands themselves. Both types of spectroscopy can be effective at identifying different polymers within a sample; however, it is important to note that NIR spectroscopy is not commonly used for the identification of microplastics [99].

MIR spectroscopy, also known as Fourier transform mid-infrared (FT-MIR) spectroscopy, can be broken down into three types: conventional stationary FT-MIR spectroscopy, FT-MIR microscopy and handheld FT-MIR. Conventional FT-MIR is the most commonly used method because it can be adapted with a variety of accessories, has short measurement times and is ideal when dealing with microplastics of $1 \mathrm{~mm}$ and larger, powders and thin films. FT-MIR microscopy differs in that it is used for microplastics between $1 \mathrm{~mm}$ and $1 \mu \mathrm{m}$ and requires more complex sample handling. More interestingly, it can be used to research the ageing process because it can isolate and analyse microplastic surfaces. Handheld FT-MIR is still in its infancy for microplastic analysis. Water (moisture) can interfere with handheld FT-MIR, which is a fundamental problem considering microplastics are most commonly found in wet or moist areas [99]. 


\subsection{Raman Spectroscopy}

Raman spectroscopy is similar to IR spectroscopy in that it utilizes vibrational bands to detect and characterize polymeric substances. However, the two types of spectroscopy differ in how those vibrational bands are interpreted. Raman spectroscopy utilizes photon scattering and the subsequent shifts between the inelastic and elastic scattering. The shift, otherwise known as the Raman shift, which corresponds to the energy differences identified by IR spectroscopy, identifies the specific polymers in a sample [100].

Raman spectroscopy can be altered for different purposes depending on the sample type and research objective. Conventional Raman spectroscopy is a straightforward process that can be used for routine microplastic sample analysis, but Coherent Anti-Stokes Raman Scattering (CARS) is a much more complicated and specific process used for living organisms and tissue samples. CARS can accurately locate and partially characterize microplastics in biological tissues without interference from the biological matrices surrounding the plastic particles. However, this approach is a demanding and expensive method that requires a more sophisticated analysis of the results. Raman microscopy, on the other hand, is another straightforward application that can significantly influence the spatial resolution and allow for nanoplastic analysis (i.e., plastic particles $<0.1 \mu \mathrm{m}$ in size) [100].

Raman spectroscopy, as compared to IR spectroscopy, has three main advantages: wider spectral coverage, better resolution and lower water interference. Raman spectroscopy is not broken down into two spectrums, and it can collect an entire vibrational range in one spectrum. The scattering (vs. energy absorption) also provides more precise vibrational bands, allowing for increased chemical information, because closely related bands can be more easily distinguished. Wet samples can also be readily used in Raman spectroscopy because the water spectrum is weakly shown and does not overtly interfere with the other vibrational bands (not the case with IR spectroscopy, where the water spectrum is relatively large and can obscure other vibrational bands). However, there are two inherent disadvantages with Raman spectroscopy: the fluorescence effect, which causes overexcitation of a sample and its impurities, and laser degradation of the sample. Although there are approaches that can overcome the fluorescence effect, many of them induce photo or thermal degradation of the sample [100].

Although there are distinct advantages and disadvantages to using either IR or Raman spectroscopy, vibrational spectroscopy as a whole is oftentimes preferred due to its non-destructive analytical methods. However, even though IR and Raman spectroscopy are the most common practices for microplastic analysis [100], other destructive methods, such as pyrolysis gas chromatography mass spectrometry (Py-GC-MS) and thermal extraction desorption gas chromatography mass spectrometry (TED-GC-MS), may be more desirable due to their more expediated processes.

\subsection{Pyrolysis Gas Chromatography Mass Spectrometry (Py-GC-MS)}

The objective of pyrolysis gas chromatography mass spectrometry (Py-GC-MS) is to identify the chemical characteristics of polymers based on their mass spectra (pyrogram). Py-GC-MS thermally decomposes polymeric substances under elevated temperatures $\left(500-1400^{\circ} \mathrm{C}\right)$ and in the presence of an inert gas, typically helium. Polymer-specific, gaseous thermal degradation products are produced and then chromatographically separated and analyzed via mass spectrometry. The resultant mass spectra or pyrogram for the tested polymer can then be compared to a library of pyrograms of known polymers and additives. Py-GC-MS is a fast method of identification that allows for the polymer type and additives used to be identified simultaneously and does not require any pre-treatment of the plastic [101-103].

The difficulty with Py-GC-MS is that it is a destructive method of analysis, meaning that the polymer samples are destroyed in the process of identification. Analysis of the size and distribution of the microplastics has to be done prior to Py-GC-MS analysis. Additionally, Py-GC-MS requires the isolation of one microplastic particle or small fragment 2-500 $\mu \mathrm{g}$ in weight, meaning that only small sample sizes can be identified at a time [94,101]. Environmental samples that contain NOM 
would require sample pre-treatment to isolate the microplastics within the sample, and then each microplastic particle or fragment would need to be tested individually, limiting its ability to be used for the identification of microplastics in large environmental samples.

Other drawbacks are the limitations of the apparatus if the pyrolizer is mounted externally to the GC-MS. The transition zone from the pyrolizer to the GC-MS is commonly a heated capillary, which has a small internal diameter (approximately $1 \mathrm{~mm}$ ) and maximum temperatures from $250-400{ }^{\circ} \mathrm{C}[104,105]$. Contamination or blockages of the capillary can occur due to condensation of polymeric degradation products with high molecular weights and boiling points higher than the maximum transfer capillary temperature. In-line or non-discriminatory Py-GC-MS apparatuses are required to help mitigate these issues but cannot always prevent the discrimination of certain polymeric degradation compounds $[103,106]$.

\subsection{Thermal Extraction Desorption Gas Chrometogrpahy Mass Spectrometry (TED-GC-MS)}

Thermal extraction desorption gas chromatography mass spectrometry (TED-GC-MS) is a newly established two-step method for microplastic analysis in environmental samples. Thermal extraction and adsorption are first achieved by thermally decomposing the sample in a thermogravimetric analyzer (TGA), where the sample is heated from room temperature to $600{ }^{\circ} \mathrm{C}$ at a constant rate and under constant conditions (with air or inert gases (nitrogen or argon) as purge gases). Once the sample is pyrolyzed, the polymer-specific, gaseous degradation products are trapped on a solid-phase adsorber. The trapped degradation products can then be chromatographically separated and analyzed using thermal desorption gas chromatography mass spectrometry (TDS-GC-MS) [104,105,107].

TED-GC-MS is a fast identification method that does not require plastic pre-treatment and allows for larger sample sizes upwards of $100 \mathrm{mg}$ to be tested. It is also more advantageous than many Py-GC-MS techniques due to the eradication of the transition zone issues. TED-GC-MS allows for the degradation products to be captured by the TGA and manually or automatically (depending on the apparatus) moved to the GC-MS [104,105,107]. However, similarly to Py-GC-MS, it is a destructive analytical method, so the size and distribution of the microplastics must be analysed beforehand. Additionally, environmental samples may require pre-treatment methods, especially if there is a significant portion of NOM present, to isolate the microplastic particles and fragments.

\section{Microplastic Discharges from WWTPs}

Wastewater is one of the primary sources for micro- and nanoplastics; therefore, studying the fate of micro- and nanoplastics in WWTPs is an important step in determining their behaviour and means of transport within the different treatment stages. It is critical to determine the fractions of microplastics leaving via the treated effluent versus the sludge, as well as where they may be accumulating in different parts of the treatment train. Carr et al. [51] demonstrated that mixed liquor samples spiked with polyethylene microplastics $(10-300 \mu \mathrm{m})$ resulted in almost complete buoyancy of the microplastics at the lab-scale. However, when microplastics $(53-63 \mu \mathrm{m})$ were used to spike synthetic, high solid influents, the partitioning of the microplastics from the mixture was only $40 \%$. The majority of the microplastics got caught in the toilet paper floc and were unable to float to the surface of the influent. These results would indicate that in high solid influents microplastics could easily move from the primary stage to the secondary stages of treatment.

Carr et al. [51] also tested a gravity bed filter at the lab-scale, and it was observed that $>95 \%$ of the microplastics $(10-300 \mu \mathrm{m})$ were retained. At full-scale, Carr et al. [51] tested secondary and tertiary effluent quality at seven different WWTPs. A total volume of $5.68 \times 10^{3} \mathrm{~L}$ unfiltered secondary effluent was filtered using two sieves $(400$ and $180 \mu \mathrm{m}$ ) resulting in one microplastic particle being identified. The return activated sludge (RAS) was also sampled and was determined to include approximately one microplastic particle per $20 \mathrm{~mL}$. A total of $1.89 \times 10^{5} \mathrm{~L}$ of tertiary effluent was analysed using three sieves (400, 180 and $45 \mu \mathrm{m})$. Tertiary treatment steps using gravity bed filters are effective at removing microplastics from $10+\mu \mathrm{m}$ at the lab-scale and $45+\mu \mathrm{m}$ at full-scale. However, the higher 
accumulation of microbial communities and vegetation at full-scale prevented further filtration due to clogging. The difficulty with only using physical means of removal is that NOM can interfere and prevent complete removal of microplastics $<45 \mu \mathrm{m}$, which is critical because microplastics can be significantly smaller (i.e., $1 \mu \mathrm{m})$ and nanoplastics even smaller $(<0.1 \mu \mathrm{m})$. Micro- and nanoplastics can still be present in large concentrations below the $45 \mu \mathrm{m}$ threshold and WWTPs are possibly discharging these plastic fibres and particles directly to the environment despite undergoing tertiary treatment.

Similarly, it was reported by Van Cauwenberghe et al. [108] that only 20\% of microplastics were removed in primary treatment, indicating that the secondary treatment was exposed to the majority of the microplastic contaminants. Talvitie et al. [109] also related similar results with approximately $30 \%$ removal during primary treatment, with the majority of polymeric fibres being removed, but only a limited number of microplastic particles. Although a large proportion of the microplastics were removed in the subsequent secondary treatment, on average there were still 4.9 fibres and 8.6 particles per litre of final effluent (smallest filter size of $20 \mu \mathrm{m}$ ). Lares et al. [63], who studied sludge and wastewater samples from a WWTP in Finland, corroborated the findings that there was minimal removal in the primary stage; however, they found that there was a higher prevalence of microplastic fibres as opposed to particles in the secondary effluent, which differs from the findings of Talvitie et al. [109]. Magnusson et al. [110] also found that there was negligible removal in the primary treatment stages of six WWTPs located in Sweden, Finland and Iceland. The Swedish WWTPs were found to have 4-68 particles $/ \mathrm{m}^{3}$, the Finnish WWTPs had 29-32 particles $/ \mathrm{m}^{3}$ and the Icelandic WWTPs had 1130-2490 particles $/ \mathrm{m}^{3}$ in final effluent (smallest filter size of $300 \mu \mathrm{m}$ ). Kalcikova et al. [55] used the removal percentages of Van Cauwenberghe et al. [108], Talvitie et al. [109] and Magnusson et al. [110] to approximate a primary microbead removal of $25 \%$ and then proceeded to model secondary treatment at the lab scale with wastewater from Ljubljana, Slovenia. They found that $13.9 \mathrm{mg}$ of microbeads $/ \mathrm{m}^{3}$ of final effluent remained (smallest microbead size of $60 \mu \mathrm{m}$ ).

Although these studies reported that there were efficient capture and removal of microplastics in liquid streams by the secondary and tertiary stages of the WWTPs, they were limited by the size of microplastics that were investigated, as well as the methods used to isolate them. Physical removal does not give the full picture of microplastics in a WWTP or its subsequent effluents. It also does not address the sub-microplastic $(<1 \mu \mathrm{m})$ and nanoplastic $(<0.1 \mu \mathrm{m})$ particles that are produced or remain in the WWTP effluents. Most significantly, the subsequent capture of the plastic particles results in their accumulation in the sludge stream, with some studies reporting that $99 \%$ of the microplastics in wastewater are retained in WWTP sludge [84]. Additionally, although the studies discussed herein all use particles per volume as a measurement, the lack of standardized procedures and reporting units makes comparison of other studies difficult. Further emphasis needs to be placed on standardization of units of measurement.

The WWTP solids obtained from primary and secondary sedimentation are collectively known as sludge. In addition to microplastics and various other contaminants, sludge contains organic matter and nutrients and is seen as a valuable resource for agricultural applications in many countries. However, in most countries raw sludge must undergo treatment before being used or disposed, which typically includes thickening, conditioning, stabilization, dewatering, drying and disinfection. Sludge treatment processes do not remove micro- and nanoplastics, and as a result, microplastics have been applied to agricultural soils for decades. Microplastic abundance in sludge has been investigated by multiple studies revealing that sludge can contain anywhere from 1500-41,000 particles/kg dw depending on the WWTP facility, location and sludge treatment methods, with the majority being microplastic fibres [85,111-113].

It has been estimated through sludge and other microplastic agricultural applications that between 63,000-430,000 tons of microplastics are applied to European soils and 44,000-300,000 to North American soils per year [114]. The large range is due to the varying sludge application rates in different countries, which can range from $0 \%$ to $91 \%$ of the total sludge production with an average 
between $43-50 \%[86,114]$. It is critical to be able to remove these plastic particles from sludge to limit the terrestrial exposure to micro- and nanoplastics or find alternative final disposal options for sludge.

\section{Freshwater and Terrestrial Microplastic Occurrence}

\subsection{Surface Water}

Microplastic occurrence in marine water bodies has been extensively researched, but more information needs to be acquired for freshwater bodies. In Canada and the United States, the Great Lakes basin has been the site of many surface water microplastic surveys all of which have utilized manta trawls or neuston nets $(333 \mu \mathrm{m})$. Hendrickson et al. [80] sampled western Lake Superior and found estuary and harbour samples ranged from $21,000-110,000$ particles $/ \mathrm{km}^{2}$ with the highest average abundance of $54,000 \pm 39,000$ particles $/ \mathrm{km}^{2}$, followed by open water samples with 25,000-54,000 particles $/ \mathrm{km}^{2}$ (avg: 38,000 $\pm 15,000$ particles $/ \mathrm{km}^{2}$ ) and then nearshore samples with 0-76,000 particles $/ \mathrm{km}^{2}$ (avg: 28,000 $\pm 21,000$ particles $/ \mathrm{km}^{2}$ ). Fibres $(39 \%$ ) were the most abundant microplastic observed, followed by fragments (34\%) and films (21\%). The open water sites had higher abundances on average than the nearshore sites, which suggests that wave and wind currents have a significant impact on the movement and congregation of microplastic particles in surface waters. Additionally, the authors speculated that the increased potential for microplastic scavenging in the nearshore sites could accelerate the movement of microplastics to the benthos and sediment zones, again contributing to the difference in open water and nearshore abundances.

Eriksen et al. [77] investigated the surface water microplastic contamination of Lake Erie, Huron and eastern Superior. Lake Erie proved to have the most concentrated microplastic contamination, from $6056-466,305$ particles $/ \mathrm{km}^{2}$ (avg: 105,503 particles $/ \mathrm{km}^{2}$ ), followed by eastern Lake Superior with 1277-12,645 particles $/ \mathrm{km}^{2}$ (avg: 5391 particles $/ \mathrm{km}^{2}$ ) and Lake Huron with 0-6541 particles $/ \mathrm{km}^{2}$ (avg: 2780 particles $/ \mathrm{km}^{2}$ ). Microplastics $0.355-0.999 \mathrm{~mm}$ in size accounted for $81 \%$ of the captured microplastics with pellets (48\%) and fragments $(42 \%)$ being the most abundant. The captured pellets were compared to the microbeads of common beauty products and found to be similar in all aspects (i.e., size, shape, texture and composition). Conversely, Hendrickson et al. [80] who surveyed western Lake Superior, found significantly greater microplastic abundances in nearshore and offshore sites than Eriksen et al. [77], and they were predominantly made up of microplastic fibres and fragments with very minimal pellets and beads. The differences in abundance between the western and eastern studies of Lake Superior could be due to the fact that the western side contains the Twin Ports and thus, significantly heavier anthropogenic activity than the eastern side; however, that does not explain why fibres (and fragments) would be most abundant in the west and pellets/beads (and fragments) in the east.

A possible cause for the stratification of fibres and pellets/beads in Lake Superior could be the wind and wave patterns of the region and lake (significant cyclonic gyres are present in eastern Lake Superior as opposed to western Lake Superior [115]), as well as the movement of fibres through the water column. Although both fibres and pellets/beads are typically composed of the same types of low-density plastics (i.e., PE $0.91-0.96 \mathrm{~g} / \mathrm{cm}^{3}$ and PP $0.91 \mathrm{~g} / \mathrm{cm}^{3}$ ) [77], enabling them to float in water, fibres have been documented as being less abundant in surface waters and more abundant in benthic zones of the same water body, whereas pellets/beads and fragments did not have that same trend [73]. It is possible that fibres, due to their long lengths and varying sizes, could become entrapped in particulate and organic matter, as well as aggregate with other fibres, resulting in faster movement through the water column as compared to pellets/beads. The pellets/beads could therefore be more easily transported and maintained in the eastern convergence zones of Lake Superior. However, further research of surface and sediment samples in the western and eastern parts of Lake Superior, as well as the spatiotemporal trends of fibres and pellets/beads in freshwater, needs to be conducted to conclusively determine the reason for the surface water stratification. 
Mason et al. [116] conducted an intensive (59 sample) survey of the surface waters of Lake Michigan resulting in microplastic contamination of 1407-100,016 particles $/ \mathrm{km}^{2}$ with an average of 17,276 particles $/ \mathrm{km}^{2}$. Similarly to the finding of Eriksen et al. [77], the majority of the microplastic particles were $0.355-0.999 \mathrm{~mm}$ in size; however, fragments $(79 \%)$ were the most abundant followed by fibres (14\%), with marginal quantities of pellets/beads. Baldwin et al. [72] also focused their efforts on the Great Lakes basin investigating 29 tributaries comprising $22 \%$ of the total tributary contribution to the Great Lakes and found similar results to Mason et al. [116] and Eriksen et al. [77] with the majority of the collected microplastics falling between $0.355-0.999 \mathrm{~mm}$ in size. However, the tributaries were different from the Great Lakes, with microplastic fibres $(71 \%)$ comprising a large majority of the microplastics found, followed by fragments $(17 \%)$.

There is significant variability in the abundance and types of microplastics present in the Great Lakes, which can be partially attributed to the varying population densities clustered within the basin, as well as the proximity of the industrial sectors to the shorelines. Equally, the variability may be caused by the differing hydraulic residence times within each lake. Lake Huron, Michigan and Superior have hydraulic residence times of 22, 62 and 186 years [117], respectively, which correspond to increasingly larger average microplastic abundances. However, Lake Erie, which has the smallest hydraulic residence time of 2.7 years, was found to have the largest abundance of microplastics. So, although hydraulic residency may be a factor, proximity to industrial areas and densely populated areas also plays a major role, especially if the accumulation of pollution exceeds the rate of turnover.

Freshwater surfaces in Europe have also shown extensive microplastic contamination. Mani et al. [118] categorized the microplastic contamination within the surface water of the Rhine River in Europe by sampling 11 sites along an $820 \mathrm{~km}$ stretch from Basel, Switzerland to Rotterdam, The Netherlands. Every sample collected contained microplastic contamination resulting in $52,364-3,931,062$ particles $/ \mathrm{km}^{2}$ with an average abundance of 892,777 particles $/ \mathrm{km}^{2}$. The microplastic abundance increased substantially at sampling points downstream, such as within the Rhine-Ruhr metropolitan area, which were heavily impacted by anthropogenic activities (domestic and industrial wastewater discharges and plastic factories). The Rhine River basin is one of the largest European river catchments, which partially or wholly encompasses nine countries (Austria, Belgium, France, Germany, Italy, Liechtenstein, Luxembourg, The Netherlands and Switzerland) [119]. Although the Great Lakes and the Rhine River are both fundamental waterways in North American and Europe, respectively, the population within the Rhine River basin is almost double that of the Great Lakes basin, with over 58 million people [119] compared to 30 million people [120], respectively. This larger population likely accounts for the significantly larger microplastic contamination discovered.

Microplastic contamination in surface waters worldwide is a common phenomenon, especially in areas with higher population densities; however, even areas with minimal anthropogenic contact are accumulating microplastics in their surface waters. Free et al. [79] investigated Lake Hovsgol located in the northern mountains of Mongolia, which has been a part of a National Park since 1992 and is very isolated from anthropogenic activity (only being close to two villages with a combined population of 5440 people). The surveyed surface waters revealed microplastic abundances ranging from $997-44,435$ particles $/ \mathrm{km}^{2}$ with an average abundance of 20,264 particles $/ \mathrm{km}^{2}$, and fragments $(40 \%)$, films (38\%) and fibres (21\%) comprised the majority of the microplastics collected. The average abundance for Lake Hovsgol exceeds the abundances found for Lakes Huron, Michigan and eastern Superior, which are surrounded by heavily urbanized areas. These results suggest that microplastics are ubiquitous freshwater contaminants.

\subsection{Groundwater}

Although there are a very limited number of studies conducted on groundwater microplastic contamination, there have been a few documented cases. Panno et al. [9] studied springs and wells $(<65 \mathrm{~m})$ from two karst aquifers in Illinois, USA and found that 16 of the 17 samples taken were contaminated with microplastic fibres $(>0.45 \mu \mathrm{m})$. On average there were 6.4 particles/L, with a 
maximum concentration of 15.2 particles/L. Due to the more open nature of karst systems (crevices, conduits, sinkholes, caves, etc.), it is suspected that septic releases and run-off were the main sources of the microplastics.

Mintenig et al. [121] investigated groundwater microplastic contamination in Holdorf, Germany from three wells $30 \mathrm{~m}$ deep. Sample sizes of $1000 \mathrm{~L}$ were taken from each of the wells and analyzed, resulting in very minimal microplastic concentrations of $0-0.007$ particles/L with an average concentration of 0.0007 particles/L. Most of the microplastic present was in the form of fragments 50-150 $\mu \mathrm{m}$ in size.

A scoping study in the North West of South Africa by Bouwman et al. [122] examined microplastic concentrations in four groundwater boreholes and found on average that there were 0.0417 fragments/L and 0.1250 fibres/L. The fragments were all $<600 \mu \mathrm{m}$; however, the fibres ranged from $20 \mu \mathrm{m}$ to $>1.5 \mathrm{~mm}$ with an increasing trend towards larger sizes.

Currently, the limited number of studies conducted on microplastics in groundwater does not allow for comparisons or conclusions to be drawn, highlighting the fact that groundwater microplastic contamination has yet to be targeted as an issue. Two billion people depend on groundwater resources worldwide for domestic, drinking, agricultural and industrial practices [65] making groundwater a critical resource. Micro- and nanoplastics are introduced into the terrestrial and freshwater environments via direct and indirect routes (see Section 6), which may then enter global aquifers (see Sections 6 and 12). Although there is limited information on the impacts of microplastics in the human body, it is only a matter of time before adverse effects are recognized either through micro- and nanoplastics themselves or through the adsorbed pollutants on these plastics. Significantly more research needs to be done in this area, especially with the inevitability of micro- and nanoplastics being transported into aquifer systems.

\subsection{Sediments}

The Great Lakes region has been the site of many microplastic surveys due to its proximity to heavily populated areas and the vastness of the Great Lakes basin, which includes Lake Ontario, Erie, Huron, Superior and Michigan. Corcoran et al. [123] analyzed two sections of beach sediments from the Humber Bay area of Lake Ontario and found on average of 15.5 microplastic pellets $/ \mathrm{m}^{2}$. Notably, a significant number of microplastic fragments $(<1 \mathrm{~cm})$ were also collected from the beach samples, but due to the size designation were not included in the microplastic abundance counts. Corcoran et al. [123] also analysed two Lake Ontario bottom sediment core samples which resulted in 241 microplastic pieces/kg dw composed of primarily PE and PP; however, microplastics were only found up to a depth of $8 \mathrm{~cm}$ correlating to 38 years of accumulation. Ballent et al. [96] also surveyed the same region of Lake Ontario and found on average that beach, nearshore and tributary sediments had 20-470 particles/kg dw (avg: 140 particles/kg dw), 40-4270 particles/kg dw (avg: 980 particles/kg $\mathrm{dw}$ ) and 40-27,830 particles/kg dw (avg: 610 particles/kg dw), respectively. Fragments and fibres were the most abundant microplastic $<2 \mathrm{~mm}$, but fragments and beads were the most abundant microplastic $>2 \mathrm{~mm}$. The nearshore sediment core samples had the highest abundance of fibres and were found to contain microplastics up to a depth of $15 \mathrm{~cm}$.

The difference in microplastic abundance between the two studies could be due to the fact that Ballent et al. [96] used a more thorough sampling regime, which included a greater number of samples (10 beach, 33 nearshore and 7 tributary at a variety of different locations in the Lake Ontario region) as well as bulk sampling methods (i.e., core, grab and trap). Corcoran et al. [123] selectively sampled two beach areas ( $25 \mathrm{~m}$ by $4 \mathrm{~m}$ and $10 \mathrm{~m}$ by $2.5 \mathrm{~m}$ to a depth of $5 \mathrm{~cm}$ ), only collecting microplastics visible to the naked eye, resulting in a potential underestimation of the actual microplastics present. Additionally, Corcoran et al. [123] did not differentiate fragments that were $<5 \mathrm{~mm}$ from fragments $<1 \mathrm{~cm}$, which also influenced the reported microplastic abundance. However, it is important to note that there was significant microplastic variation between the types of sampling techniques employed by Ballent et al. [96] for nearshore sediment samples. Nearshore samples collected with gravity cores 
(2130 particles/kg dw) had higher microplastic abundances than trap (1070 particles/kg dw) and grab (730 particles/kg dw) samples.

Seven popular beaches along the shoreline of Lake Huron were surveyed by Zbyszewski and Corcoran [124]. Only four had microplastic present, and Sarnia beach accounted for $94 \%$ of the microplastic abundance with 408 microplastic pellets $/ \mathrm{m}^{2}$. Lake Erie and Lake St. Clair were also surveyed by Zbyszewski et al. [125], which revealed significant microplastic pellet abundance. The majority of the pellets identified in the sediments of Lake Huron, Erie and St. Clair were located at beaches that were in close proximity to industrial facilities in Canada and the United States specializing in plastic production, indicating a correlation between the abundance of microplastic pellets and the proximity to the industrial sectors.

Dean et al. [126] examined beach, nearshore and tributary sediments of the northern shorelines of Lake Erie and found that there were 50-146 particles $/ \mathrm{kg} \mathrm{dw}, 0-391$ particles $/ \mathrm{kg} \mathrm{dw}$ and $10-462$ particles $/ \mathrm{kg} \mathrm{dw}$, respectively. The majority of the microplastics present in beach and nearshore sediments were made up of fibres (63\% and $64 \%$, respectively) followed by fragments ( $37 \%$ and $36 \%$, respectively). Tributary samples differed in that fragments were the most abundant (62\%), followed by fibres (37\%) and beads (1\%). The major difference between Dean et al. [126] and Zbyszewski et al. [125] were sampling techniques and locations along the shorelines of Lake Erie. Zbyszewski et al. [125] found the highest abundance of pellets on the Southern shoreline, which Dean et al. [126] did not sample. Additionally, Dean et al. [126] did not use a grid sampling technique, but rather grab and trap sampling.

Microplastic pollution has also been identified in freshwater sediments and shorelines worldwide. The beaches surrounding Lake Garda in Northern Italy, which is an in-land subalpine lake used as a drinking water source and tourist attraction, were analyzed for microplastic contamination [127]. The northern shoreline had an average of $1108 \pm 983$ microplastic particles $/ \mathrm{m}^{2}$ and the southern shoreline had $108 \pm 55$ microplastic particles $/ \mathrm{m}^{2}$, predominantly comprising fragments, with some fibres from fishing gear. Conversely, Lakes Bolsena and Chiusi in Central Italy were analyzed and found to have more fibres than fragments [78]. Lake Bolsena had on average $638 \pm 323$ fragments $/ \mathrm{m}^{2}$ and $1284 \pm 421$ fibres $/ \mathrm{m}^{2}$, and Lake Chiusi $625 \pm 310$ fragments $/ \mathrm{m}^{2}$ and $1492 \pm 542$ fibres $/ \mathrm{m}^{2}$. The difference could be due to the location of the lakes and the proximity to populated areas, where more fibres will be present due to clothing and other material items. However, similar to the description of Lake Huron by Zbyszewski and Corcoran [124], one of the surveyed beaches of Lake Garda accounted for the majority of the microplastic contamination. Differing from Zbyszewski and Corcoran [124] is the location of the lake, which is isolated from industrial sectors, suggesting that another source, such as the wave and wind currents within the lake and surrounding region, could be accountable for differing abundances.

Other areas such as South America and China have also documented significant microplastic pollution in freshwater sediments. Blettler et al. [128] looked at the beach sediments of a floodplain lake (Setúbal Lake) along the Paraná River in Central South America using a grid sampling approach. Fragments, fibres and foam microplastics proved to be the most abundant with an average of 704 particles $/ \mathrm{m}^{2}$. Zhang et al. [129] analyzed lakeshore sediments from some of the isolated Tibetan Plateau lakes, specifically Geren Co, Wuru Co, Siling Co and Mujiu Co, and found on average $42 \pm 47$ particles $/ \mathrm{m}^{2}, 117 \pm 126$ particles $/ \mathrm{m}^{2}, 563 \pm 1219$ particles $/ \mathrm{m}^{2}$ and $17 \pm 20$ particles $/ \mathrm{m}^{2}$, respectively. The majority of the microplastic particles collected were fragments with some fibres relating to fishing gear, similar to the study of Lake Garda, suggesting that fibres are more predominant in areas where there is a higher population density due to the vast quantity of clothing and materials present. Due to the remoteness of the locations and lack of anthropogenic activity, it was speculated that the lakes were contaminated via river flow as well as atmospheric deposition or fallout.

Differences in microplastic types as well as differences in abundance in freshwater locations are characteristic of the river and lake flow patterns, as well as the wind patterns in the area. The proximity of industrial sectors and densely populated areas or the popularity of the freshwater site also play a significant role in the deposition and movement of microplastic in sediments. 
However, the different sampling procedures and lack of standardization of the same sampling techniques make study comparisons very difficult and, therefore, inhibit the ability to make concrete conclusions. Standardizing sediment sampling and mitigating microplastic contamination is of the utmost importance. Some attempts at standardizing have been made, such as the case study by Imhof et al. [130] that analyzed microplastic abundances in different zones of the Lake Garda beach sediments. It was found that the water line and high-water line showed variability, sometimes containing microplastics and other times having none, whereas the drift line, which is between the water line and high-water line, always contained microplastic contamination. The suggestion by Imhof et al. [130] was to centralize beach sediment sampling on drift lines to help ensure consistency between studies. Of course, this would only be a standardization of the location and not the sampling techniques used, additionally, and more lakes would need to be analyzed to confirm that drift lines are more representative than other sediment zones.

\subsection{Soil}

Soil has not been as heavily investigated as sediment samples despite the known usage of macroand microplastics within agricultural practices. Only a few studies have looked at the abundance of microplastics within agricultural fields that have utilized plastics in some form. Liu et al. [131] looked into microplastic contamination $(20 \mu \mathrm{m}-5 \mathrm{~mm})$ of farmland soils from the suburbs of Shanghai that utilized mulching film (two fields 1-5 years, twelve fields 5-9 years and five fields $>10$ years continuous use) and contained large amounts of discarded macroplastics. They found $78.0 \pm 12.9$ particles $/ \mathrm{kg}$ $\mathrm{dw}$ in shallow soil $(0-3 \mathrm{~cm})$ and $62.5 \pm 13.0$ particles/ $\mathrm{kg} \mathrm{dw}$ in deeper soil $(3-6 \mathrm{~cm})$. Fibres $(53 \%)$ and fragments (38\%) were the most abundant, followed by films $(7 \%)$ and pellets $(2 \%)$, with microplastics $<1 \mathrm{~mm}$ significantly more abundant in the deeper soils. The lack of mulching film microplastics, despite the known usage, may indicate that mulching film contaminates soils far less than fibres and fragments. Additionally, the incidence of smaller microplastics in the deeper levels of soils indicates that small microplastics $(<1 \mathrm{~mm})$ and nanoplastics $(<0.1 \mu \mathrm{m})$ may infiltrate soils at a faster rate. The proximity of the farmlands to the densely populated city of Shanghai and the possible use of irrigation water contaminated with fibres could be the cause of the abundance of microplastic fibres in the soil. It is also possible that the farmlands may have utilized sludge application for fertilizer; however, the authors did not fully know the practices of the farmers.

Huang et al. [132] also investigated the abundance of microplastics due to the continuous application of film mulching, but over 5-, 15- and 24-year periods in cotton fields in Shihezi, Xinjiang Uygur Autonomous Region, China. The 5-year fields were sampled from 0-5, 5-20 and 20-40 cm resulting in average abundances of $61.9 \pm 20.6,102.9 \pm 69.4$, and $68.0 \pm 41.4$ pieces $/ \mathrm{kg} \mathrm{dw}$, respectively, and no significant differences at depth. In the 5-, 15- and 24-year periods there was an average abundance of $80.3 \pm 49.3,308 \pm 138.1$ and $1075.6 \pm 346.8$ pieces $/ \mathrm{kg} \mathrm{dw}$, respectively, indicating that the continuous application of film mulching over time results in accumulated microplastic abundance in the soils. Huang et al. [132] was able to determine that the microplastics' chemical composition matched the plastic film mulching chemical composition, suggesting that they did originate from the plastic film; however the types of microplastics (i.e., fibre, fragment, film, etc.) were not identified. Sample comparison between Liu et al. [131] and Huang et al. [132] is difficult due to the fact that sampling depths and film mulching time periods differ between the two studies; however, the 5-year fields from $0-5 \mathrm{~cm}$ are comparable to the results obtained by Liu et al. [131].

Zhang and Liu [111] surveyed croplands at the upstream and estuary of the Chai River in China, as well as a converted cropland to woodland buffer zone in the estuary. The croplands, Dunshang, Shangusan, Dagoujian and Anle, had experienced intensive agricultural practices consisting of high crop intensity and exposure to greenhouses with plastic film shedding enclosures; however, irrigation practices and sewage sludge application rates differed. Dagoujian and Anle were irrigated with the effluent from the decentralized domestic wastewater treatment systems (DDWTS) of the surrounding villages, and Dunshang and Shangusan with the surface water of the Chai River. All four croplands 
used sewage sludge as fertilizer; however, Dagoujian and Anle were reported to have a higher frequency of use. Dagoujian and Anle had 13,470-42,960 particles/kg dw (avg: 26,760 particles/kg dw), whereas Dunshang and Shangusan had 7100-26,630 particles/kg dw (avg: 12,960 particles/kg dw). The buffer zone, which was located closest to Dagoujian, had 8180-18,100 particles/kg dw (avg: 14,360 particles/kg $\mathrm{dw})$. Ultimately, all results suggest that the higher the exposure to microplastic applications, the higher the microplastic abundance in the soil. Fibres comprised $92 \%$ of the microplastics collected and $95 \%$ of the collected microplastics were $<1 \mathrm{~mm}$, with the majority between $0.05-0.25 \mathrm{~mm}$. Similarly, Corradini et al. [112] investigated 30 agricultural fields in Mellipilla, Chile that had documented sludge application rates. They found that the higher the number of sludge applications, the higher the abundance of microplastics $(<2 \mathrm{~mm})$ present in the soils, with fibres comprising $97 \%$ of the microplastics quantified.

Other studies have quantified microplastic contamination in farmlands and soils that have not been subjected to intentional microplastic and plastic applications. Piehl et al. [133] investigated farmland in Germany which was only exposed to conventional agricultural practices, meaning that the farmland was never exposed to microplastic-containing fertilizers, such as biosolids and organic fertilizers, or agricultural plastic applications, such as greenhouses, nets and mulching films. In addition, the farmland was only rainfed, so potential contamination from other irrigation practices (such as the use of WWTP effluent or surface waters) was also avoided. The abundance of microplastics from the top $5 \mathrm{~cm}$ of soil ranged from $0-1.25$ particles $/ \mathrm{kg} \mathrm{dw}$ with an average of 0.34 particles $/ \mathrm{kg} \mathrm{dw}$. Microplastic fragments and films were the most abundant, with only two fibres being found within the samples, and the most abundant polymer type was PE followed by PP and PS. The vast differences in microplastic abundance between farmlands applying microplastics and plastics versus those that do not is significant. Intensive agricultural practices are a primary method of introducing vast quantities of microplastics (and nanoplastics) into the terrestrial environment.

Scheurer and Bigalke [134] also focused on areas without intentional application of microplastics or plastics in the Swiss floodplains. Twenty-nine nature reserve sites across Switzerland were studied and it was found that $90 \%$ of the sites contained microplastic contamination with upwards of 593 particles $/ \mathrm{kg} \mathrm{dw}$. Eighty-five percent of the microplastics found ranged between $125-500 \mu \mathrm{m}$, and $88 \%$ of the microplastics were composed of PE. The obvious source of contamination for the floodplains were the surrounding rivers and tributaries, demonstrating that tributaries are a primary source of microplastic transportation from freshwater to terrestrial environments.

\section{Fate and Behaviour of Micro- and Nanoplastics and Their Ecological Implications}

Research on the fate and behaviour of micro- and nanoplastics in soil and sediment environments is scarce. The limited studies that have been published have predominantly focused on the role of sedimentary organisms in the movement of micro- and nanoplastics in soils. Sedimentary organisms play a critical role in the movement and transport of microplastics to deeper soil depths. Yu et al. [135] studied the movement of LDPE microplastics $(1 \mathrm{~mm}-250 \mu \mathrm{m}, 250-150 \mu \mathrm{m},<150 \mu \mathrm{m})$ in sandy soils (94.40\% sand, $3.20 \%$ silt and $2.40 \%$ clay) due to earthworm (Lumbricus terrestris) burrowing. LDPE microbeads were added to the surface of the soil with dry litter (Populusnigra) resulting in a microplastic concentration of $7 \% \mathrm{w} / \mathrm{w}$. They found that the movement and burrowing of earthworms resulted in significant movement of LDPE particles from the surface of the sample to the bottom of the sample (50 cm vertical movement) in 14 days. The earthworms greatly increased the concentration of microplastics at depth. However, the earthworms showed a tendency to move smaller particles $(<250 \mu \mathrm{m})$ resulting in a gradient of microplastics with depth. Rillig et al. [136] had similar results when analyzing earthworms (Lumbricus terrestris) in soils (73.6\% sand, $18.8 \%$ silt and 7.6\% clay) collected from fields in Berlin when they added LDPE microbeads (710-850 $\mu \mathrm{m}, 1180-1400 \mu \mathrm{m}, 1700-2000 \mu \mathrm{m}$ and 2360-2800 $\mu \mathrm{m}$ ) and dry litter (Populusnigra) to the surface of the sample resulting in a microplastic concentration of $15 \% \mathrm{w} / \mathrm{w}$. The earthworms had a positive effect on the movement of LDPE microbeads from the surface to the bottom of the sample, with preferential movement of smaller LDPE microbeads 
to the lowest depths. Interestingly, Rillig et al. [136] noticed that the transport of microplastics was not only from ingestion and subsequent egestion, but also via adherence to the exterior of the earthworms. The study of Maaß et al. [137], although conducted with collembolan species (Folsomia candida and Proisotoma minuta), which are a type of micro-arthropod, also found that soil-dwelling organisms have a significant impact on the movement of microplastics $(<200 \mu \mathrm{m})$. The significance of these studies is that they imply a more significant problem: contamination of soil and groundwater sources through soil-dwelling organism transport. Critically these studies were only able to quantify the transport of microplastics, which leaves many questions regarding the fate of nanoplastics in soils. It could be that the preference for smaller particles would mean that nanoplastics will, if they are not already, pervade the deepest depths of soils and enter groundwater sources.

Weather patterns and the influence of water on soils, as well as the physio-chemical properties of soils, have also been investigated as a means of accelerated vertical movement of microplastics. O'Connor et al. [138] studied the impact of wet-dry cycles on sediment contaminated with PE and PP microbeads $(21-535 \mu \mathrm{m})$ and discovered there was a direct correlation between the number of wet-dry cycles and the depth of microplastics penetration-an increase in wet-dry cycles increased the penetration depth. It was also noted that the smaller the microplastic particles the deeper the penetration. These findings suggest that not only do sedimentary organisms accelerate the vertical migration of microplastics, but so too does water infiltration. Rainfall events may be working in tandem with sedimentary organisms to transport micro- and nanoplastics through the vadose zone to groundwater sources. These results may also be extrapolated and applied to beach sediments, which are continually exposed to wet-dry cycles due to their proximity to waterbodies and the subsequent change of water levels and tides.

Wu et al. [139] investigated the movement of polystyrene nanoplastics (100 nm) in desert ( $\mathrm{pH} 9.75$; iron (Fe) 2.69\% and aluminum (Al) 12.6\%), black ( $\mathrm{pH}$ 6.57; Fe 4.04\% and $\mathrm{Al} 15.9 \%$ ) and red (pH 4.97; $\mathrm{Fe} 6.57 \%$ and $\mathrm{Al} 26.9 \%$ ) soils and determined that the soil mineral content (specifically relating to $\mathrm{Fe} / \mathrm{Al}$ oxides) and $\mathrm{pH}$ levels were critical to the movement of polystyrene nanoplastics. The higher the $\mathrm{pH}$ and the lower the Fe/Al oxide content, the higher the movement of the nanoplastics in the soil. Although this study focused explicitly on polystyrene nanoplastics, which are not representative of other polymeric substances or particle sizes, it demonstrates the complexity of plastic retention and movement through soil matrices. There are a multitude of factors that have the power to aid or impede the movement of micro- and nanoplastics depending on the interactions of the soil and the plastic. Therefore, it is imperative that the physio-chemical properties of soils are further analysed to understand how they interact with micro- and nanoplastics of differing characteristics and compositions.

Another issue relating to the presence of micro- and nanoplastics in the environment is that they can also alter the physio-chemical properties of sediments. Microplastics cause an increase in sediment permeability as well as a decrease in maximal temperature. The heat absorbency of sediments contaminated with microplastics decreases, which can have extreme effects on biota. Soil temperature determines the sex of many animals' eggs (i.e., turtles and alligators) and many sediment-dwelling biota may dry out due to the excess permeability [59]. These types of changes can have drastic impacts to food webs and cause significant legacy affects.

The fate and behaviour of micro- and nanoplastics in freshwater and terrestrial environments need to be more fully explored, but the current literature indicates that there are complex ecological interactions that govern the movement, accumulation and impacts of micro- and nanoplastics in sediments and soils. Soil-dwelling organisms, water infiltration and soil physio-chemical characteristics all play a critical part in the fate and behaviour of micro- and nanoplastics. However, further research needs to be conducted on the differing polymeric compositions and types of micro- and nanoplastics in these environments. Understanding how all types of plastic interact with the environment is critical to understanding their fate and behaviours, as well as influencing how and when certain types of plastic may be utilised in agricultural or other anthropogenic activities. 


\section{Health Impacts}

\subsection{Microplastics}

The majority of the microplastics found in organisms are fibres or fragments [95], resulting in many environmental and health implications. Any biota that consumes microplastics can suffer from gastrointestinal tract issues and obstruction, potentially leading to false satiety, starvation and death [3]. However, this only considers the physical implications of the microplastic and does not take into account the chemical effects. Plasticides can easily migrate away from plastics and cause deleterious consequences to biota. Many of the additives are lipophilic and can penetrate cell membranes and interfere with biochemical reactions occurring in the cells, resulting in behavioural and reproductive issues [37]. PVC, PS and PC have toxic monomers that can cause reproductive abnormalities and potentially cancer $[21,22]$. Once the microplastic is in the gastrointestinal tract it can leach plastic additives, as well as any toxin that it may have adsorbed when discharged to the environment (i.e., persistent organic pollutants (POPs)). Many of these additives and POPs are toxic to biota and can cause abnormalities [3], which in turn, could lead to potential death of the organism.

The majority of the studies conducted on microplastic health impacts have focused on marine life; however, there have been some studies regarding the impacts on freshwater and terrestrial life. Browne et al. [140] studied the impact on lugworms (Arenicola marina) exposed to sediment contaminated with $5 \% \mathrm{w} / \mathrm{w}$ PVC particles $(230 \mu \mathrm{m})$ pre-sorbed with pollutants (nonylphenol and phenanthrene) and typical industrial additives triclosan (0-5\%) and flame retardant polybrominated diphenyl ether (PBDE)-47 (5-30\%), and found that the pollutants and additives desorbed from the PVC and entered the tissues of the lugworms. The exposure to these additives and pollutants resulted in decreased functionality within sediments, higher susceptibility to pathogens, increased oxidative stress and a 55\% increase in mortality. In contrast, Rodriguez-Seijo et al. [141] studied the impacts of LDPE pellets (250-1000 $\mu \mathrm{m}$ ) on earthworms (Eisenia andrei) in sediment up to $0.1 \% \mathrm{w} / \mathrm{w}$ and found that there were no adverse effects on reproduction, survival and growth; however, there was evidence of epithelial damage and inflammation within the gastrointestinal tract, as well as a triggered immune response. The difference in microplastic concentrations could be the reason why there was less of an impact in the study conducted by Rodriguez-Seijo et al. [141], but the different type of plastic, lack of chemical additives and pre-sorbed pollutants, and the differing lugworm species, could also play a critical role. However, based on these two studies, we can see the adverse effects on lugworms when exposed to microplastics and their additives. Additionally, in both of these studies, there was no documented evidence of microplastic accumulation within the earthworms. The reason for this may be due to the size of the microplastics tested. Larger microplastics when ingested could effectively block, and accumulate within, the gastrointestinal tract of sedimentary organisms, but more research is required in this area. Bioaccumulation effects due to microplastics entering food networks (i.e., accumulating in bottom feeders such as sedimentary organisms), and building from one level to the next is a possibility, but has also yet to be fully explored for freshwater and terrestrial life.

Multiple studies have been published that look at the ingestion of microplastics by birds in the terrestrial environment [142-144]; however, none investigated the toxicity, stress, or response of the birds to the microplastic ingestion. Conversely, mammals, such as mice [145], rats [146] and dogs [147], were investigated for toxicity of small microplastics, and serious implications were found. PS microbeads ( $5 \mu \mathrm{m}$ and $20 \mu \mathrm{m}$ ) were mixed in the drinking water of 70 mice and were found to accumulate in the liver, kidney and gut. The accumulations resulted in inflammation and damage to the organs, which negatively impacted their functionality; however, it did not result in death within the 4-week testing period. Similarly, latex particles $(2 \mu \mathrm{m})$ in water were administered to rats revealing significant intestinal uptake of the particles. Dogs that were administered microplastics $(15-75 \mu \mathrm{m})$ also showed evidence of particles being transported by the lymphatic system and the portal system of the intestines. It is significant that the plastic particles were found in the hepatic portal vein because this vein carries blood from the gastro-intestinal tract, gallbladder, pancreas and spleen directly to the liver. 
Once there is intestinal uptake of microplastics, the reality is that the particles can then be transported throughout the body and accumulate in organs and tissues. Alarmingly, microplastics are not normally discussed as being capable of penetrating the gastro-intestinal tract; however, these studies have found that microplastics $<75 \mu \mathrm{m}$ are very capable of accumulating within the body. These early findings suggest that there is a potential threat to human health, but more research needs to be conducted to shrink the knowledge gap.

\subsection{Nanoplastics}

Nanoplastics pose a more significant threat to biota than microplastics due to their increasingly small size. It is well known that plasticides are capable of penetrating cell membranes [37] and nanoplastics are also capable of this. Both nanoplastics and plasticides have the potential to enter and accumulate in every part of any organism. Recent studies have shown that small latex particles $(<50 \mathrm{~nm})$ can accumulate in Japanese rice fish (testes, liver, blood and brain) [148], as well as cause decreased survival rates to their embryos [149]. Most alarmingly, the blood-brain barrier was breached in Japanese rice fish, and such a breaching poses extreme health risks to all animals and humans. Other studies have found that nanoplastics can cause behavioural, physiological and metabolic shifts in fish such as crucian carp (Carassius carassius) [150,151], severe developmental defects in sea urchin (Paracentrotus lividus) embryos [152], growth inhibition in green algae (Chlorella sp. and Scenedesmus sp.) $[153,154]$ and decreased fertility and reproduction rates in crustaceans Daphnia magna [154] and Tigriopus japonicus [155]. Although all of these studies have focused on marine biota, it is anticipated that all terrestrial life forms living in or close to water sources will experience similar issues as marine organisms when exposed to nanoplastics.

The health of any environment or ecosystem is highly dependent on the biota that lives within it, so the health impacts associated with micro- and nanoplastics will cause ecosystems to suffer along with organisms. The critical food chains and networks may suffer, and deterioration of the organisms will induce the deterioration of the ecosystem. Furthermore, although microplastics cannot penetrate plant cell walls and have minimal impacts on flora, nanoplastics have been shown to penetrate plant cell walls [4]. The difference with flora as compared to fauna is that each plant's uptake varies depending on a multitude of factors: root volume, density and surface area, xylem volume, surface area and sap $\mathrm{pH}$, transpiration, growth rate, water and lipid fractions and sorption potential, plasmalemma (bio-membrane) potential, tonoplast potential, $\mathrm{pH}$ of the cytoplasm and vacuoles [156]. The vast differences between plants make it difficult to pinpoint the impacts that nanoplastics may cause; however, some studies using engineered carbonaceous nanoparticles, similar in size, shape and surface functional groups to microplastics, have been documented in whole plants (i.e., rice (Oryza sativa) [157], maize (Zea mays), soybean (Glycine max) and thale cress (Arabidopsis thaliana) [158]) and thought to have entered by one of the following pathways: endocytosis through the plasmodesmata, ion transport channels, carrier proteins or aquaporins, and soil carbon or root exudate mediation [4]. However, very few studies have been conducted on the toxicity, stress and response of plants to nanoplastics.

\section{Regulations}

The European Union (EU) has long been at the forefront of environmental sustainability and reducing plastic pollution. A circular economy model was implemented in the EU in 2018 which stipulates that all plastic products will be designed for longer durability, reuse and effective recycling and that all packaging materials within the EU market will be reusable and/or recyclable by 2030 [159,160]. The European Commission has required that industries involved in plastic production or recycling must come forward with an "ambitious and concrete set of voluntary commitments to back the strategy and its vision for 2030" [160]. In other words, the onus is on the designers and manufacturers to produce reusable and recyclable plastic products for consumers and to eliminate their current business model of single-use plastics. 
European countries, such as Belgium, France, Ireland, Italy, Sweden and the United Kingdom (UK), as well as Canada, New Zealand, South Korea and the United States of American (USA) are among the countries to implement restrictions on the intentional use of microplastics in cosmetics and personal hygiene products in the last five years [161]. As of 22 August 2019, the European Chemicals Agency (ECHA) has proposed an extensive restriction and ban on the intentional use of microplastics in the EU. The proposal targets products that are made of or mixed with microplastics, including, but not limited to, fertilizers and their additives, plant protection products and coated seeds, cosmetic products, detergents and cleaning supplies, waxes and polishes, paints and coatings, construction products, medical devices, medicinal products and food supplements [161].

In addition, several international organizations such as G7, G20, the United Nations, and the Arctic Council are taking steps to advance policy to reduce or prevent plastic pollution in the environment. Some of these initiatives include the G7 Ocean Plastics Charter, the Arctic Council Desktop Study on Marine Litter including Microplastics in the Arctic, the G20 Implementation Framework for Actions on Marine Plastic Litter, the United Nations Global Partnership on Marine Litter, and the United Nations Sustainable Development Goals.

\section{Solutions to Plastic Waste}

Based on the findings of the extensive literature review presented above, it is clear that plastic waste has a wide range of adverse impacts on freshwater and terrestrial ecosystems as well as on humans, and we cannot continue current practices of plastics production, use and disposal in a throw-away culture. International organizations, governments, businesses and civil society need to come together to agree on and implement a long-term and sustainable plastic waste management strategy. It will be necessary to adopt a life cycle approach that includes recovery, reuse, recycling and end-of-life disposal and management options. Collection and recovery of used plastics from waste streams and the environment, and their reprocessing for new uses, will help to decrease greenhouse gases and save energy and resources. Research and innovation will play a critical role in prevention of plastic waste (i.e., increasing durability, developing biodegradable plastics), monitoring (i.e., sensors and instruments), and reprocessing and repurposing (i.e., new technologies, energy recovery) of plastic waste. Finally, education of the public and increasing awareness will help to minimize the use of single-use and disposable plastic products, replacing them with reusable, recyclable, and compostable products.

\section{Conclusions}

Plastic has become one of the most prevalent and deleterious environmental contaminants, pervading all aquatic and terrestrial environments. Its many forms and additives, as well as its varying sources, pathways and sinks, have made it difficult to evaluate and quantify. Among the limited research studies available on plastic pollution, the marine environment has been the primary focus to date and there is a need to fill the knowledge gap regarding the quantities, fate, transport and impact of micro-and nanoplastics in freshwater and terrestrial ecosystems.

The increasingly smaller size of plastics in the natural environment pose many issues for accurate sampling and analysis, which limits the ability to mitigate harmful impacts associated with their presence. An emphasis on small micro- and nanoplastics in future research is imperative to be able to develop precise sampling and quantification techniques. The standardization of micro- and nanoplastic sampling and analysis, including units of measurement, is critical for building an accurate database of information and understanding the health implications for both ecosystems and humans.

Author Contributions: Conceptualization, K.B. and B.Ö.; resources, K.B. and B.Ö.; writing-original draft preparation, K.B.; writing—review and editing, K.B. and B.Ö.; visualization, K.B. and B.Ö.; supervision, B.Ö.; project administration, K.B. and B.Ö.; funding acquisition, B.Ö. All authors have read and agreed to the published version of the manuscript. 
Funding: This research was funded by Natural Sciences and Research Council of Canada (NSERC) under the CREATE program (Grant number: 498017-2017).

Conflicts of Interest: The authors declare no conflict of interest.

\section{References}

1. American Chemical Society. THE BAKELIZER; American Chemical Society: Washington, DC, USA, 1993.

2. PlasticsEurope. PlasticsEurope Plastics-The Facts 2018: An Analysis of European Plastics Production, Demand and Waste Data; PlasticsEurope: Brussels, Belgium, 2018. Available online: https://www.plasticseurope.org/ application/files/6315/4510/9658/Plastics_the_facts_2018_AF_web.pdf (accessed on 20 September 2020).

3. Da Costa, J.P.; Duarte, A.C.; Rocha-Santos, T.A.P. Microplastics-Occurence, Fate and Behaviour in the Environment. In Comprehensive Analytical Chemistry; Rocha-Santos, T.A.P., Duarte, A.C., Eds.; Elsevier B.V.: Amsterdam, The Netherlands, 2017; Volume 75, pp. 1-24.

4. Ng, E.L.; Huerta-Lwanga, E.; Eldridge, S.M.; Johnston, P.; Hu, H.-W.; Geissen, V.; Chen, D. An overview of microplastic and nanoplastic pollution in agroecosystems. Sci. Total Environ. 2018, 627, 1377-1388. [CrossRef] [PubMed]

5. He, D.; Luo, Y.; Lu, S.; Liu, M.; Song, Y.; Lei, L. Microplastics in soils: Analytical methods, pollution characteristics and ecological risks. Trends Anal. Chem. 2018, 109, 163-172. [CrossRef]

6. Chae, Y.; An, Y.-J. Current research trends on plastic pollution and ecological impacts on the soil ecosystem: A review. Environ. Pollut. 2018, 240, 387-395. [CrossRef] [PubMed]

7. Kosuth, M.; Mason, S.A.; Wattenberg, E. V Anthropogenic contamination of tap water, beer, and sea salt. PLoS ONE 2018, 13, 1-18. [CrossRef] [PubMed]

8. Koelmans, A.A.; Hazimah, N.; Nor, M.; Hermsen, E.; Kooi, M.; Mintenig, S.M.; France, J. De Microplastics in freshwaters and drinking water: Critical review and assessment of data quality. Water Res. 2019, 155, 410-422. [CrossRef]

9. Panno, S.V.; Kelly, W.R.; Scott, J.; Zheng, W.; McNeish, R.E.; Holm, N.; Hoellein, T.J.; Baranski, E.L.; McNeish, R.E. Microplastic Contamination in Karst Groundwater Systems. Groundwater 2019, 57, 189-196. [CrossRef]

10. Eerkes-Medrano, D.; Leslie, H.; Quinn, B. Microplastics in drinking water: A review and assessment. Curr. Opin. Environ. Sci. Health 2019, 7, 69-75. [CrossRef]

11. Hurley, R.R.; Nizzetto, L. Fate and occurrence of micro(nano)plastics in soils: Knowledge gaps and possible risks. Curr. Opin. Environ. Sci. Health 2018, 1, 6-11. [CrossRef]

12. Bläsing, M.; Amelung, W. Plastics in soil: Analytical methods and possible sources. Sci. Total Environ. 2018, 612, 422-435. [CrossRef]

13. Horton, A.A.; Walton, A.; Spurgeon, D.J.; Lahive, E.; Svendsen, C. Microplastics in freshwater and terrestrial environments: Evaluating the current understanding to identify the knowledge gaps and future research priorities. Sci. Total Environ. 2017, 586, 127-141. [CrossRef] [PubMed]

14. Vert, M.; Doi, Y.; Hellwich, K.-H.; Hess, M.; Hodge, P.; Kubisa, P.; Rinaudo, M.; Schué, F. Terminology for biorelated polymers and applications (IUPAC Recommendations 2012). Pure Appl. Chem. 2012, 84, 377-410. [CrossRef]

15. Vroman, I.; Tighzert, L. Biodegradable Polymers. Materials 2009, 2, 307-344. [CrossRef]

16. Iwata, T. Biodegradable and Bio-Based Polymers: Future Prospects of Eco-Friendly Plastics. Angew. Chem. Int. Ed. 2015, 54, 3210-3215. [CrossRef] [PubMed]

17. Phuong, N.N.; Zalouk-Vergnoux, A.; Poirier, L.; Kamari, A.; Châtel, A.; Mouneyrac, C.; Lagarde, F. Is there any consistency between the microplastics found in the field and those used in laboratory experiments? Environ. Pollut. 2016, 211, 111-123. [CrossRef] [PubMed]

18. Environment and Climate Change Canada; Health Canada. Draft Science Assessment of Plastic Pollution; Government of Canada: Ottawa, ON, Canada, 2020.

19. European Commission. Environmental and Health Risks of Microplastic Pollution; Independent Expert Report; European Commission: Brussels, Belgium, 2019.

20. European Commission. Report from the Commission to the European Parliament and the Council on the Impact of the Use of Oxo-Degradable Plastic, Including Oxo-Degradable Carrier Bags, on the Environment; Final Report; European Commission: Brussels, Belgium, 2018. 
21. Tyree, C.; Morrison, D. Invisibles: The Plastic inside US; Orb Media, Inc.: Washington, DC, USA, 2018.

22. Seaman, G. Plastics by the Numbers. Available online: https://learn.eartheasy.com/articles/plastics-by-thenumbers/ (accessed on 1 June 2019).

23. Rochester, J.R.; Bolden, A.L. Bisphenol S and F: A Systematic Review and Comparison of the Hormonal Activity of Bisphenol A Substitutes. Environ. Health Perspect. 2015, 123, 643-650. [CrossRef] [PubMed]

24. Bauer, M.; Herrmann, R. Estimation of the environmental contamination by phthalic acid esters leaching from household wastes. Sci. Total Environ. 1997, 208, 49-57. [CrossRef]

25. Mendoza, L.M.R.; Taniguchi, S.; Karapanagioti, H.K. Advanced Analytical Techniques for Assessing the Chemical Compounds Related to Microplastics. In Comprehensive Analytical Chemistry; Rocha-Santos, T.A.P., Duarte, A.C., Eds.; Elsevier: Amsterdam, The Netherlands, 2017; pp. $209-240$.

26. Heskett, M.; Takada, H.; Yamashita, R.; Yuyama, M.; Ito, M.; Geok, Y.B.; Ogata, Y.; Kwan, C.; Heckhausen, A.; Taylor, H.; et al. Measurement of persistent organic pollutants (POPs) in plastic resin pellets from remote islands: Toward establishment of background concentrations for International Pellet Watch. Mar. Pollut. Bull. 2012, 64, 445-448. [CrossRef]

27. Ogata, Y.; Takada, H.; Mizukawa, K.; Hirai, H.; Iwasa, S.; Endo, S.; Mato, Y.; Saha, M.; Okuda, K.; Nakashima, A.; et al. International Pellet Watch: Global monitoring of persistent organic pollutants (POPs) in coastal waters. 1. Initial phase data on PCBs, DDTs, and HCHs. Mar. Pollut. Bull. 2009, 58, 1437-1446. [CrossRef]

28. Karapanagioti, H.; Endo, S.; Ogata, Y.; Takada, H. Diffuse pollution by persistent organic pollutants as measured in plastic pellets sampled from various beaches in Greece. Mar. Pollut. Bull. 2011, 62, 312-317. [CrossRef]

29. Hirai, H.; Takada, H.; Ogata, Y.; Yamashita, R.; Mizukawa, K.; Saha, M.; Kwan, C.; Moore, C.; Gray, H.; Laursen, D.; et al. Organic micropollutants in marine plastics debris from the open ocean and remote and urban beaches. Mar. Pollut. Bull. 2011, 62, 1683-1692. [CrossRef]

30. Fisner, M.; Taniguchi, S.; Majer, A.P.; Bícego, M.C.; Turra, A. Concentration and composition of polycyclic aromatic hydrocarbons (PAHs) in plastic pellets: Implications for small-scale diagnostic and environmental monitoring. Mar. Pollut. Bull. 2013, 76, 349-354. [CrossRef] [PubMed]

31. Fisner, M.; Taniguchi, S.; Moreira, F.; Bícego, M.C.; Turra, A. Polycyclic aromatic hydrocarbons (PAHs) in plastic pellets: Variability in the concentration and composition at different sediment depths in a sandy beach. Mar. Pollut. Bull. 2013, 70, 219-226. [CrossRef] [PubMed]

32. Rios, L.M.; Moore, C.; Jones, P.R. Persistent organic pollutants carried by synthetic polymers in the ocean environment. Mar. Pollut. Bull. 2007, 54, 1230-1237. [CrossRef] [PubMed]

33. Rochman, C.M.; Lewsion, R.; Eriksen, M.; Allen, H.; Cook, A.-M.; Teh, S.J. Polybrominated diphenyl ethers (PBDEs) in fish tissue may be an indicator of plastic contamination in marine habitats. Sci. Total Environ. 2014, 476-477, 622-633. [CrossRef] [PubMed]

34. Endo, S.; Takizawa, R.; Okuda, K.; Takada, H.; Chiba, K.; Kanehiro, H.; Ogi, H.; Yamashita, R.; Date, T. Concentration of polychlorinated biphenyls (PCBs) in beached resin pellets: Variability among individual particles and regional differences. Mar. Pollut. Bull. 2005, 50, 1103-1114. [CrossRef] [PubMed]

35. Da Costa, J.P.; Santos, P.S.M.; Duarte, A.C.; Rocha-Santos, T. (Nano)plastics in the environment-Sources, fates and effects. Sci. Total Environ. 2016, 566-567, 15-26. [CrossRef]

36. Kaczmarek, H.; Bajer, K.; Gałka, P.; Kotnowska, B. Photodegradation studies of novel biodegradable blends based on poly(ethylene oxide) and pectin. Polym. Degrad. Stab. 2007, 92, 2058-2069. [CrossRef]

37. Lambert, S.; Sinclair, C.; Boxall, A. Occurrence, Degradation, and Effect of Polymer-Based Materials in the Environment. In Reviews of Environmental Contamination and Toxicology; Springer: New York, NY, USA, 2014; Volume 227, pp. 1-54, ISBN 9783319013268.

38. Jakubowicz, I. Evaluation of degradability of biodegradable polyethylene (PE). Polym. Degrad. Stab. 2003, 80, 39-43. [CrossRef]

39. Brunner, I.; Fischer, M.; Rüthi, J.; Stierli, B.; Frey, B. Ability of fungi isolated from plastic debris floating in the shoreline of a lake to degrade plastics. PLoS ONE 2018, 13, e0202047. [CrossRef]

40. Barnes, D.K.A.; Galgani, F.; Thompson, R.C.; Barlaz, M. Accumulation and fragmentation of plastic debris in global environments. Philos. Trans. R. Soc. B Biol. Sci. 2009, 364, 1985-1998. [CrossRef]

41. Rocha-Santos, T.; Duarte, A.C. A critical overview of the analytical approaches to the occurrence, the fate and the behavior of microplastics in the environment. Trends Anal. Chem. 2015, 65, 47-53. [CrossRef] 
42. Claessens, M.; De Meester, S.; Van Landuyt, L.; De Clerck, K.; Janssen, C.R. Occurrence and distribution of microplastics in marine sediments along the Belgian coast. Mar. Pollut. Bull. 2011, 62, 2199-2204. [CrossRef] [PubMed]

43. Ryan, P.G.; Moore, C.J.; Van Franeker, J.A.; Moloney, C.L. Monitoring the abundance of plastic debris in the marine environment. Philos. Trans. R. Soc. B Biol. Sci. 2009, 364, 1999-2012. [CrossRef] [PubMed]

44. Derraik, J.G.B. The pollution of the marine environment by plastic debris: A review. Mar. Pollut. Bull. 2002, 44, 842-852. [CrossRef]

45. Graham, E.R.; Thompson, J.T. Deposit- and suspension-feeding sea cucumbers (Echinodermata) ingest plastic fragments. J. Exp. Mar. Biol. Ecol. 2009, 368, 22-29. [CrossRef]

46. Wang, Z.; Taylor, S.E.; Sharma, P.; Flury, M. Poor extraction efficiencies of polystyrene nano- and microplastics from biosolids and soil. PLoS ONE 2018, 13, e0208009. [CrossRef]

47. Andrady, A.L. Microplastics in the marine environment. Mar. Pollut. Bull. 2011, 62, 1596-1605. [CrossRef]

48. Rodríguez-Seijo, A.; Pereira, R. Morphological and Physical Characterization of Microplastics. In Comprehensive Analytical Chemistry; Rocha-Santos, T.A.P., Duarte, A.C., Eds.; Elsevier BV: Amsterdam, The Netherlands, 2017; Volume 75, pp. 49-66.

49. Liedermann, M.; Gmeiner, P.; Pessenlehner, S.; Haimann, D.M.; Hohenblum, P.; Habersack, H. A Methodology for Measuring Microplastic Transport in Large or Medium Rivers. Water 2018, 10, 414. [CrossRef]

50. Dris, R.; Gasperi, J.; Rocher, V.; Tassin, B. Synthetic and non-synthetic anthropogenic fibers in a river under the impact of Paris Megacity: Sampling methodological aspects and flux estimations. Sci. Total Environ. 2018, 618, 157-164. [CrossRef]

51. Carr, S.A.; Liu, J.; Tesoro, A.G. Transport and fate of microplastic particles in wastewater treatment plants. Water Res. 2016, 91, 174-182. [CrossRef]

52. Duis, K.; Coors, A. Microplastics in the aquatic and terrestrial environment: Sources (with a specific focus on personal care products), fate and effects. Environ. Sci. Eur. 2016, 28, 1-25. [CrossRef] [PubMed]

53. Ziajahromi, S.; Neale, P.A.; Rintoul, L.; Leusch, F.D. Wastewater treatment plants as a pathway for microplastics: Development of a new approach to sample wastewater-based microplastics. Water Res. 2017, 112, 93-99. [CrossRef] [PubMed]

54. Mason, S.A.; Garneau, D.; Sutton, R.; Chu, Y.; Ehmann, K.; Barnes, J.; Fink, P.; Papazissimos, D.; Rogers, D.L. Microplastic pollution is widely detected in US municipal wastewater treatment plant effluent. Environ. Pollut. 2016, 218, 1045-1054. [CrossRef]

55. Kalčíková, G.; Alič, B.; Skalar, T.; Bundschuh, M.; Gotvajn, A. Žgajnar Wastewater treatment plant effluents as source of cosmetic polyethylene microbeads to freshwater. Chemosphere 2017, 188, 25-31. [CrossRef] [PubMed]

56. Dubaish, F.; Liebezeit, G. Suspended Microplastics and Black Carbon Particles in the Jade System, Southern North Sea. Water Air Soil Pollut. 2013, 224, 1-8. [CrossRef]

57. Foitzik, M.-J.; Unrau, H.-J.; Gauterin, F.; Dörnhöfer, J.; Koch, T. Investigation of ultra fine particulate matter emission of rubber tires. Wear 2018, 87-95. [CrossRef]

58. Wagner, S.; Hüffer, T.; Klöckner, P.; Wehrhahn, M.; Hofmann, T.; Reemtsma, T. Tire wear particles in the aquatic environment-A review on generation, analysis, occurrence, fate and effects. Water Res. 2018, 139, 83-100. [CrossRef]

59. Cole, M.; Lindeque, P.; Halsband, C.; Galloway, T.S. Microplastics as contaminants in the marine environment: A review. Mar. Pollut. Bull. 2011, 62, 2588-2597. [CrossRef]

60. Stephens, B.; Azimi, P.; El Orch, Z.; Ramos, T. Ultrafine particle emissions from desktop 3D printers. Atmos. Environ. 2013, 79, 334-339. [CrossRef]

61. Isobe, A. Percentage of microbeads in pelagic microplastics within Japanese coastal waters. Mar. Pollut. Bull. 2016, 110, 432-437. [CrossRef]

62. Sun, J.; Dai, X.; Wang, Q.; Van Loosdrecht, M.C.; Ni, B.-J. Microplastics in wastewater treatment plants: Detection, occurrence and removal. Water Res. 2019, 152, 21-37. [CrossRef] [PubMed]

63. Lares, M.; Ncibi, M.C.; Sillanpää, M.; Sillanpää, M. Occurrence, identification and removal of microplastic particles and fibers in conventional activated sludge process and advanced MBR technology. Water Res. 2018, 133, 236-246. [CrossRef]

64. Anderson, J.; Park, B.J.; Palace, V.P. Microplastics in aquatic environments: Implications for Canadian ecosystems. Environ. Pollut. 2016, 218, 269-280. [CrossRef] [PubMed] 
65. Re, V. Shedding light on the invisible: Addressing the potential for groundwater contamination by plastic microfibers. Hydrogeol. J. 2019, 27, 2719-2727. [CrossRef]

66. Andrady, A.L. The plastic in microplastics: A review. Mar. Pollut. Bull. 2017, 119, 12-22. [CrossRef] [PubMed]

67. McCormick, A.R.; Hoellein, T.; London, M.G.; Hittie, J.; Scott, J.W.; Kelly, J.J. Microplastic in surface waters of urban rivers: Concentration, sources, and associated bacterial assemblages. Ecosphere 2016, 7, 1-11. [CrossRef]

68. Dris, R.; Gasperi, J.; Saad, M.; Mirande, C.; Tassin, B. Synthetic fibers in atmospheric fallout: A source of microplastics in the environment? Mar. Pollut. Bull. 2016, 104, 290-293. [CrossRef]

69. Dris, R.; Gasperi, J.; Mirande, C.; Mandin, C.; Guerrouache, M.; Langlois, V.; Tassin, B. A first overview of textile fibers, including microplastics, in indoor and outdoor environments. Environ. Pollut. 2017, 221, 453-458. [CrossRef]

70. Eerkes-Medrano, D.; Thompson, R.C.; Aldridge, D.C. Microplastics in freshwater systems: A review of the emerging threats, identification of knowledge gaps and prioritisation of research needs. Water Res. 2015, 75, 63-82. [CrossRef]

71. Hidalgo-Ruz, V.; Gutow, L.; Thompson, R.C.; Thiel, M. Microplastics in the Marine Environment: A Review of the Methods Used for Identification and Quantification. Environ. Sci. Technol. 2012, 46, 3060-3075. [CrossRef]

72. Baldwin, A.K.; Corsi, S.R.; Mason, S.A. Plastic Debris in 29 Great Lakes Tributaries: Relations to Watershed Attributes and Hydrology. Environ. Sci. Technol. 2016, 50, 10377-10385. [CrossRef] [PubMed]

73. Hoellein, T.; McCormick, A.R.; Hittie, J.; London, M.G.; Scott, J.W.; Kelly, J.J. Longitudinal patterns of microplastic concentration and bacterial assemblages in surface and benthic habitats of an urban river. Freshw. Sci. 2017, 36, 491-507. [CrossRef]

74. Anderson, P.J.; Warrack, S.; Langen, V.; Challis, J.K.; Hanson, M.L.; Rennie, M.D. Microplastic contamination in Lake Winnipeg, Canada. Environ. Pollut. 2017, 225, 223-231. [CrossRef] [PubMed]

75. Cable, R.N.; Beletsky, D.; Beletsky, R.; Wigginton, K.; Locke, B.W.; Duhaime, M.B. Distribution and Modeled Transport of Plastic Pollution in the Great Lakes, the World's Largest Freshwater Resource. Front. Environ. Sci. 2017, 5, 1-18. [CrossRef]

76. Dris, R.; Gasperi, J.; Rocher, V.; Saad, M.; Renault, N.; Tassin, B. Microplastic contamination in an urban area: A case study in Greater Paris. Environ. Chem. 2015, 12, 592. [CrossRef]

77. Eriksen, M.; Mason, S.A.; Wilson, S.; Box, C.; Zellers, A.; Edwards, W.J.; Farley, H.; Amato, S. Microplastic pollution in the surface waters of the Laurentian Great Lakes. Mar. Pollut. Bull. 2013, 77, 177-182. [CrossRef]

78. Fischer, E.K.; Paglialonga, L.; Czech, E.; Tamminga, M. Microplastic pollution in lakes and lake shoreline sediments-A case study on Lake Bolsena and Lake Chiusi (central Italy). Environ. Pollut. 2016, 213, 648-657. [CrossRef]

79. Free, C.M.; Jensen, O.P.; Mason, S.A.; Eriksen, M.; Williamson, N.; Boldgiv, B. High-levels of microplastic pollution in a large, remote, mountain lake. Mar. Pollut. Bull. 2014, 85, 156-163. [CrossRef]

80. Hendrickson, E.; Minor, E.C.; Schreiner, K. Microplastic Abundance and Composition in Western Lake Superior As Determined via Microscopy, Pyr-GC/MS, and FTIR. Environ. Sci. Technol. 2018, 52, 1787-1796. [CrossRef]

81. Estahbanati, S.; Fahrenfeld, N. Influence of wastewater treatment plant discharges on microplastic concentrations in surface water. Chemosphere 2016, 162, 277-284. [CrossRef]

82. Dyachenko, A.; Mitchell, J.; Arsem, N. Extraction and identification of microplastic particles from secondary wastewater treatment plant (WWTP) effluent. Anal. Methods 2017, 9, 1412-1418. [CrossRef]

83. Simon, M.; Van Alst, N.; Vollertsen, J. Quantification of microplastic mass and removal rates at wastewater treatment plants applying Focal Plane Array (FPA)-based Fourier Transform Infrared (FT-IR) imaging. Water Res. 2018, 142, 1-9. [CrossRef] [PubMed]

84. Magnusson, K.; Norén, F. Screening of Microplastic Particles in and Down-Stream a Wastewater Treatment Plant; IVL Swedish Environmental Research Institute: Stockholm, Sweden, 2014. Available online: https: //www.diva-portal.org/smash/get/diva2:773505/FULLTEXT01.pdf (accessed on 20 September 2020).

85. Mahon, A.M.; Connell, B.O.; Healy, M.G.; Connor, I.O.; Officer, R.; Nash, R.; Morrison, L. Microplastics in Sewage Sludge: Effects of Treatment. Environ. Sci. Technol. 2017, 51, 810-818. [CrossRef] [PubMed] 
86. Hurley, R.R.; Lusher, A.L.; Olsen, M.; Nizzetto, L. Validation of a Method for Extracting Microplastics from Complex, Organic-Rich, Environmental Matrices. Environ. Sci. Technol. 2018, 52, 7409-7417. [CrossRef]

87. Ng, K.; Obbard, J. Prevalence of microplastics in Singapore's coastal marine environment. Mar. Pollut. Bull. 2006, 52, 761-767. [CrossRef]

88. Leslie, H.A.; Van Velzen, M.J.M.; Vethaak, A.D. Microplastic Survey of the Dutch Environment. Novel Data Set of Microplastics in North Sea Sediments, Treated Wastewater Effluents and Marine Biota; IVM: Amsterdam, The Netherlands, 2013. Available online: https://research.vu.nl/en/publications/microplastic-survey-of-thedutch-environment-novel-data-set-of-mi (accessed on 20 September 2020).

89. Nuelle, M.-T.; Dekiff, J.H.; Rémy, D.; Fries, E. A new analytical approach for monitoring microplastics in marine sediments. Environ. Pollut. 2014, 184, 161-169. [CrossRef]

90. Qiu, Q.; Peng, J.; Yu, X.; Chen, F.; Wang, J.; Dong, F. Occurrence of microplastics in the coastal marine environment: First observation on sediment of China. Mar. Pollut. Bull. 2015, 98, 274-280. [CrossRef]

91. Cole, M.; Webb, H.; Lindeque, P.; Fileman, E.; Halsband, C.; Galloway, T.S. Isolation of microplastics in biota-rich seawater samples and marine organisms. Sci. Rep. 2014, 4, 1-8. [CrossRef]

92. Tagg, A.S.; Harrison, J.P.; Ju-Nam, Y.; Sapp, M.; Bradley, E.L.; Sinclair, C.J.; Ojeda, J.J. Fenton's reagent for the rapid and efficient isolation of microplastics from wastewater. Chem. Commun. 2017, 53, 372-375. [CrossRef]

93. Rodrigues, M.; Gonçalves, A.; Gonçalves, F.J.M.; Nogueira, H.I.S.; Marques, J.; Abrantes, N. Effectiveness of a methodology of microplastics isolation for environmental monitoring in freshwater systems. Ecol. Indic. 2018, 89, 488-495. [CrossRef]

94. Löder, M.G.J.; Gerdts, G. Methodology Used for the Detection and Identification of Microplastics-A Critical Appraisal. In Marine Anthropogenic Litter; Springer Science and Business Media LLC: Berlin, Germany, 2015; pp. 201-227, ISBN 9783319165103.

95. Burns, E.E.; Boxall, A.B. Microplastics in the aquatic environment: Evidence for or against adverse impacts and major knowledge gaps. Environ. Toxicol. Chem. 2018, 37, 2776-2796. [CrossRef] [PubMed]

96. Ballent, A.; Corcoran, P.L.; Madden, O.; Helm, P.A.; Longstaffe, F.J. Sources and sinks of microplastics in Canadian Lake Ontario nearshore, tributary and beach sediments. Mar. Pollut. Bull. 2016, 110, 383-395. [CrossRef] [PubMed]

97. Song, Y.K.; Hong, S.H.; Jang, M.; Han, G.M.; Rani, M.; Lee, J.; Shim, W.J. A comparison of microscopic and spectroscopic identification methods for analysis of microplastics in environmental samples. Mar. Pollut. Bull. 2015, 93, 202-209. [CrossRef] [PubMed]

98. Lenz, R.; Enders, K.; Stedmon, C.A.; MacKenzie, D.M.; Nielsen, T.G. A critical assessment of visual identification of marine microplastic using Raman spectroscopy for analysis improvement. Mar. Pollut. Bull. 2015, 100, 82-91. [CrossRef] [PubMed]

99. Renner, G.; Schmidt, T.C.; Schram, J. Characterization and Quantification of Microplastics by Infrared Spectroscopy. In Comprehensive Analytical Chemistry; Elsevier BV: Amsterdam, The Netherlands, 2017; Volume 75, pp. 67-118.

100. Ribeiro-Claro, P.; Nolasco, M.M.; Araújo, C. Characterization of Microplastics by Raman Spectroscopy. In Comprehensive Analytical Chemistry; Rocha-Santos, T.A.P., Duarte, A.C., Eds.; Elsevier: Amsterdam, The Netherlands, 2017; Volume 75, pp. 119-151.

101. Kusch, P. Application of Pyrolysis-Gas Chromatography/Mass Spectrometry (Py-GC/MS). In Comprehensive Analytical Chemistry; Rocha-Santos, T.A.P., Duarte, A.C., Eds.; Elsevier: Amsterdam, The Netherlands, 2017; Volume 75, pp. 169-207.

102. Fries, E.; Dekiff, J.H.; Willmeyer, J.; Nuelle, M.T.; Ebert, M.; Remy, D. Identification of polymer types and additives in marine microplastic particles using pyrolysis-GC/MS and scanning electron microscopy. Environ. Sci. Process. Impacts 2013, 15, 1949-1956. [CrossRef] [PubMed]

103. Beyer, D.; Eckerle, P.; Cortes, H.; Engewald, W.; Dettmer, K. Development and applications of an automated in-column pyrolysis gas chromatography-mass spectrometry system. Chromatographia 2005, 62, 417-422. [CrossRef]

104. Dümichen, E.; Eisentraut, P.; Gerhard, C.; Barthel, A.; Senz, R.; Braun, U. Fast identification of microplastics in complex environmental samples by a thermal degradation method. Chemosphere 2017, 174, 572-584. [CrossRef] 
105. Duemichen, E.; Eisentraut, P.; Celina, M.; Braun, U. Automated thermal extraction-desorption gas chromatography mass spectrometry: A multifunctional tool for comprehensive characterization of polymers and their degradation products. J. Chromatogr. A 2019, 1592, 133-142. [CrossRef]

106. Parsi, Z.; Hartog, N.; Górecki, T.; Poerschmann, J. Analytical pyrolysis as a tool for the characterization of natural organic matter-A comparison of different approaches. J. Anal. Appl. Pyrolysis 2007, 79, 9-15. [CrossRef]

107. Duemichen, E.; Braun, U.; Senz, R.; Fabian, G.; Sturm, H. Assessment of a new method for the analysis of decomposition gases of polymers by a combining thermogravimetric solid-phase extraction and thermal desorption gas chromatography mass spectrometry. J. Chromatogr. A 2014, 1354, 117-128. [CrossRef]

108. Van Cauwenberghe, L.; Van Echelpoel, W.; De Gussem, K.; De Gueldre, G.; Vandegehuchte, M.B.; Janssen, C.R. Microplastics in Biological Wastewater Treatment Plant and the Receiving Freshwater Environment in Flanders, Belgium. In Proceedings of the SETAC EUROPE 25th Annual Meeting, Barcelona, Spain, 3-7 May 2015.

109. Talvitie, J.; Heinonen, M.; Pääkkönen, J.-P.P.; Vahtera, E.; Mikola, A.; Setälä, O.; Vahala, R. Do wastewater treatment plants act as a potential point source of microplastics? Preliminary study in the coastal Gulf of Finland, Baltic Sea. Water Sci. Technol. 2015, 72, 1495-1504. [CrossRef] [PubMed]

110. Magnusson, K.; Jörundsdóttir, H.; Norén, F.; Lloyd, H.; Talvitie, J.; Setälä, O. Microlitter in Sewage Treatment Systems: A Nordic Perspective on Waste Water Treatment Plants as Pathways for Microscopic Anthropogenic Particles to Marine Systems; Nordic Council of Ministers: Copenhagen, Denmark, 2016; ISBN 978-9-28934-490-6.

111. Zhang, G.S.; Liu, Y.F. The distribution of microplastics in soil aggregate fractions in southwestern China. Sci. Total Environ. 2018, 642, 12-20. [CrossRef] [PubMed]

112. Corradini, F.; Meza, P.; Eguiluz, R.; Casado, F.; Huerta-Lwanga, E.; Geissen, V. Evidence of microplastic accumulation in agricultural soils from sewage sludge disposal. Sci. Total Environ. 2019, 671, 411-420. [CrossRef]

113. Zubris, K.A.V.; Richards, B.K. Synthetic fibers as an indicator of land application of sludge. Environ. Pollut. 2005, 138, 201-211. [CrossRef] [PubMed]

114. Nizzetto, L.; Futter, M.; Langaas, S. Are agricultural soils dumps for microplastics of urban origin? Environ. Sci. Technol. 2016, 50, 10777-10779. [CrossRef]

115. Bennington, V.; McKinley, G.A.; Kimura, N.; Wu, C.H. General circulation of Lake Superior: Mean, variability, and trends from 1979 to 2006. J. Geophys. Res. Ocean. 2010, 115, 1-14. [CrossRef]

116. Mason, S.A.; Kammin, L.; Eriksen, M.; Aleid, G.; Wilson, S.; Box, C.; Williamson, N.; Riley, A. Pelagic plastic pollution within the surface waters of Lake Michigan, USA. J. Great Lakes Res. 2016, 42, 753-759. [CrossRef]

117. Quinn, F.H. Hydraulic Residence Times for the Laurentian Great Lakes. J. Great Lakes Res. 1992, 18, $22-28$. [CrossRef]

118. Mani, T.; Hauk, A.; Walter, U.; Burkhardt-Holm, P. Microplastics profile along the Rhine River. Sci. Rep. 2015, 5, 1-7. [CrossRef]

119. Uehlinger, U.; Wantzen, K.M.; Leuven, R.S.E.W.; Arndt, H. The Rhine River Basin; Elsevier: Amsterdam, The Netherlands, 2009; ISBN 9780123694492.

120. US EPA Facts and Figures about the Great Lakes. Available online: https://www.epa.gov/greatlakes/factsand-figures-about-great-lakes (accessed on 10 May 2020).

121. Mintenig, S.M.; Löder, M.G.J.; Primpke, S.; Gerdts, G. Low numbers of microplastics detected in drinking water from ground water sources. Sci. Total Environ. 2019, 648, 631-635. [CrossRef]

122. Bouwman, H.; Minnaar, K.; Bezuidenhout, C.; Verster, C. Microplastics in Freshwater Environments-A Scoping Study. 2018. Available online: http://www.wrc.org.za/wp-content/uploads/mdocs/2610-1-18.pdf (accessed on 20 September 2020).

123. Corcoran, P.L.; Norris, T.; Ceccanese, T.; Walzak, M.J.; Helm, P.A.; Marvin, C.H. Hidden plastics of Lake Ontario, Canada and their potential preservation in the sediment record. Environ. Pollut. 2015, 204, 17-25. [CrossRef] [PubMed]

124. Zbyszewski, M.; Corcoran, P.L. Distribution and degradation of fresh water plastic particles along the beaches of Lake Huron, Canada. Water Air Soil Pollut. 2011, 220, 365-372. [CrossRef]

125. Zbyszewski, M.; Corcoran, P.L.; Hockin, A. Comparison of the distribution and degradation of plastic debris along shorelines of the Great Lakes, North America. J. Great Lakes Res. 2014, 40, 288-299. [CrossRef] 
126. Dean, B.Y.; Corcoran, P.L.; Helm, P.A. Factors influencing microplastic abundances in nearshore, tributary and beach sediments along the Ontario shoreline of Lake Erie. J. Great Lakes Res. 2018, 44, 1002-1009. [CrossRef]

127. Imhof, H.K.; Ivleva, N.P.; Schmid, J.; Niessner, R.; Laforsch, C. Contamination of beach sediments of a subalpine lake with microplastic particles. Curr. Biol. 2013, 23, R867-R868. [CrossRef]

128. Blettler, M.C.M.; Ulla, M.A.; Rabuffetti, A.P.; Garello, N. Plastic pollution in freshwater ecosystems: Macro-, meso-, and microplastic debris in a floodplain lake. Environ. Monit. Assess. 2017, 189, 581. [CrossRef]

129. Zhang, K.; Su, J.; Xiong, X.; Wu, X.; Wu, C.; Liu, J. Microplastic pollution of lakeshore sediments from remote lakes in Tibet plateau, China. Environ. Pollut. 2016, 219, 450-455. [CrossRef]

130. Imhof, H.K.; Wiesheu, A.C.; Anger, P.M.; Niessner, R.; Ivleva, N.P.; Laforsch, C. Variation in plastic abundance at different lake beach zones-A case study. Sci. Total Environ. 2018, 613-614, 530-537. [CrossRef]

131. Liu, M.; Lu, S.; Song, Y.; Lei, L.; Hu, J.; Lv, W.; Zhou, W.; Cao, C.; Shi, H.; Yang, X.; et al. Microplastic and mesoplastic pollution in farmland soils in suburbs of Shanghai, China. Environ. Pollut. 2018, 242, 855-862. [CrossRef]

132. Huang, Y.; Liu, Q.; Jia, W.; Yan, C.; Wang, J. Agricultural plastic mulching as a source of microplastics in the terrestrial environment. Environ. Pollut. 2020, 260, 114096. [CrossRef]

133. Piehl, S.; Leibner, A.; Löder, M.G.J.; Dris, R.; Bogner, C.; Laforsch, C. Identification and quantification of macro- and microplastics on an agricultural farmland. Sci. Rep. 2018, 8, 1-9. [CrossRef] [PubMed]

134. Scheurer, M.; Bigalke, M. Microplastics in Swiss Floodplain Soils. Environ. Sci. Technol. 2018, 52, 3591-3598. [CrossRef] [PubMed]

135. Yu, M.; Van Der Ploeg, M.; Lwanga, E.H.; Yang, X.; Zhang, S.; Ma, X.; Ritsema, C.J.; Geissen, V. Leaching of microplastics by preferential flow in earthworm (Lumbricus terrestris) burrows. Environ. Chem. 2019, 16, 31-40. [CrossRef]

136. Rillig, M.C.; Ziersch, L.; Hempel, S. Microplastic transport in soil by earthworms. Sci. Rep. 2017, 7, 1-6. [CrossRef] [PubMed]

137. Maaß, S.; Daphi, D.; Lehmann, A.; Rillig, M.C. Transport of microplastics by two collembolan species. Environ. Pollut. 2017, 225, 456-459. [CrossRef]

138. O'Connor, D.; Pan, S.; Shen, Z.; Song, Y.; Jin, Y.; Wu, W.M.; Hou, D. Microplastics undergo accelerated vertical migration in sand soil due to small size and wet-dry cycles. Environ. Pollut. 2019, 249, 527-534. [CrossRef]

139. Wu, X.; Lyu, X.; Li, Z.; Gao, B.; Zeng, X.; Wu, J.; Sun, Y. Transport of polystyrene nanoplastics in natural soils: Effect of soil properties, ionic strength and cation type. Sci. Total Environ. 2020, 707, 136065. [CrossRef]

140. Browne, M.A.; Niven, S.J.; Galloway, T.S.; Rowland, S.J.; Thompson, R.C. Report microplastic moves pollutants and additives to worms, reducing functions linked to health and biodiversity. Curr. Biol. 2013, 23, 2388-2392. [CrossRef]

141. Rodriguez-Seijo, A.; Lourenço, J.; Rocha-Santos, T.A.P.; Da Costa, J.; Duarte, A.C.; Vala, H.; Pereira, R. Histopathological and molecular effects of microplastics in Eisenia andrei Bouché. Environ. Pollut. 2017, 220, 495-503. [CrossRef]

142. Zhao, S.; Zhu, L.; Li, D. Microscopic anthropogenic litter in terrestrial birds from Shanghai, China: Not only plastics but also natural fibers. Sci. Total Environ. 2016, 550, 1110-1115. [CrossRef]

143. Holland, E.R.; Mallory, M.L.; Shutler, D. Plastics and other anthropogenic debris in freshwater birds from Canada. Sci. Total Environ. 2016, 571, 251-258. [CrossRef] [PubMed]

144. Reynolds, C.; Ryan, P.G. Micro-plastic ingestion by waterbirds from contaminated wetlands in South Africa. Mar. Pollut. Bull. 2018, 126, 330-333. [CrossRef] [PubMed]

145. Deng, Y.; Zhang, Y.; Lemos, B.; Ren, H. Tissue accumulation of microplastics in mice and biomarker responses suggest widespread health risks of exposure. Sci. Rep. 2017, 7, 1-10. [CrossRef] [PubMed]

146. Carr, K.; Smyth, S.; McCullough, M.; Morris, J.; Moyes, S. Morphological aspects of interactions between microparticles and mammalian cells intestinal uptake and onward movement. Prog. Histochem. Cytochem. 2012, 46, 185-252. [CrossRef]

147. Volkheimer, G. Passage of Particles through the Wall of the Gastrointestinal Tract. Environ. Health Perspect. 1974, 9, 215. [PubMed]

148. Kashiwada, S. Distribution of nanoparticles in the see-through medaka (Oryzias latipes). Environ. Health Perspect. 2006, 114, 1697-1702. [CrossRef] 
149. Manabe, M.; Tatarazako, N.; Kinoshita, M. Uptake, excretion and toxicity of nano-sized latex particles on medaka (Oryzias latipes) embryos and larvae. Aquat. Toxicol. 2012, 105, 576-581. [CrossRef]

150. Mattsson, K.; Ekvall, M.T.; Hansson, L.A.; Linse, S.; Malmendal, A.; Cedervall, T. Altered behavior, physiology, and metabolism in fish exposed to polystyrene nanoparticles. Environ. Sci. Technol. 2015, 49, 553-561. [CrossRef]

151. Cedervall, T.; Hansson, L.A.; Lard, M.; Frohm, B.; Linse, S. Food chain transport of nanoparticles affects behaviour and fat metabolism in fish. PLoS ONE 2012, 7, 1-6. [CrossRef]

152. Della Torre, C.; Bergami, E.; Salvati, A.; Faleri, C.; Cirino, P.; Dawson, K.A.; Corsi, I. Accumulation and embryotoxicity of polystyrene nanoparticles at early stage of development of sea urchin embryos Paracentrotus lividus. Environ. Sci. Technol. 2014, 48, 12302-12311. [CrossRef]

153. Bhattacharya, P.; Lin, S.; Turner, J.P.; Ke, P.C. Physical adsorption of charged plastic nanoparticles affects algal photosynthesis. J. Phys. Chem. C 2010, 114, 16556-16561. [CrossRef]

154. Besseling, E.; Wang, B.; Lürling, M.; Koelmans, A.A. Nanoplastic affects growth of S. obliquus and reproduction of D. magna. Environ. Sci. Technol. 2014, 48, 12336-12343. [CrossRef] [PubMed]

155. Lee, K.W.; Shim, W.J.; Kwon, O.Y.; Kang, J.H. Size-dependent effects of micro polystyrene particles in the marine copepod tigriopus japonicus. Environ. Sci. Technol. 2013, 47, 11278-11283. [CrossRef] [PubMed]

156. Trapp, S. Modelling uptake into roots and subsequent translocation of neutral and ionisable organic compounds. Pest. Manag. Sci. 2000, 56, 767-778. [CrossRef]

157. Lin, S.; Reppert, J.; Hu, Q.; Hudson, J.S.; Reid, M.L.; Ratnikova, T.A.; Rao, A.M.; Luo, H.; Ke, P.C. Uptake, translocation, and transmission of carbon nanomaterials in rice plants. Small 2009, 5, 1128-1132. [CrossRef]

158. Zhao, Q.; Ma, C.; White, J.C.; Dhankher, O.P.; Zhang, X.; Zhang, S.; Xing, B. Quantitative evaluation of multi-wall carbon nanotube uptake by terrestrial plants. Carbon N. Y. 2017, 114, 661-670. [CrossRef]

159. Scientific Advice Mechanism (SAM). Microplastic Pollution: The Policy Context—Background Paper. 2018. Available online: https://ec.europa.eu/research/sam/pdf/topics/microplastic_pollution_policy-context.pdf (accessed on 20 September 2020).

160. European Commission. Communication from the Commission to the European Parliament, the Council, the European Economic and Social Committee snd the Committee of the Regions: A European Strategy for Plastics in a Circular Economy; European Commission: Brussels, Belgium, 2018; Volume SWD.

161. [ECHA] European Chemicals Agency. Annex to the Annex XV Restriction Report; European Chemicals Agency: Helsinki, Finland, 2019. 